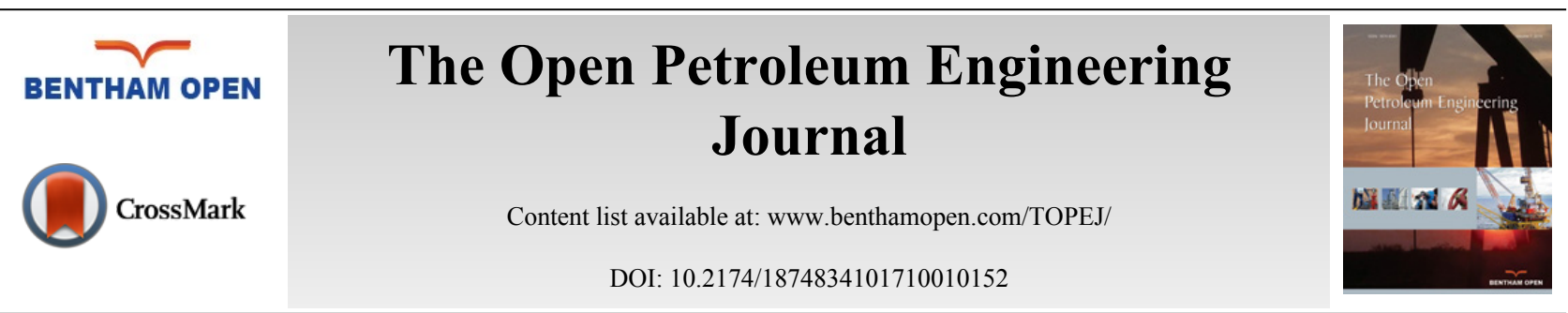

RESEARCH ARTICLE

\title{
Inflow Performance Relationship Correlation for Solution Gas-Drive Reservoirs Using Non-Parametric Regression Technique
}

\author{
Ahmed M. Daoud ${ }^{1, *}$, Mahmoud Abdel Salam², Abdel Alim Hashem ${ }^{1}$ and M.H. Sayyouh ${ }^{1}$ \\ ${ }^{I}$ Department of Petroleum Engineering, Cairo University, Giza, EGYPT \\ ${ }^{2}$ Ganoub ElWadi Petroleum Company, Cairo, EGYPT
}

Received: March 28, 2017

Revised: May 08, 2017

Accepted: June 13, 2017

\begin{abstract}
:
Background:

The Inflow Performance Relationship (IPR) describes the behavior of flow rate with flowing pressure, which is an important tool in understanding the well productivity. Different correlations to model this behavior can be classified into empirically-derived and analytically-derived correlations. The empirically-derived are those derived from field or simulation data. The analytically-derived are those derived from basic principle of mass balance that describes multiphase flow within the reservoir. The empirical correlations suffer from the limited ranges of data used in its generation and they are not function of reservoir rock and fluid data that vary per each reservoir. The analytical correlations suffer from the difficulty of obtaining their input data for its application.
\end{abstract}

\section{Objectives:}

In this work, the effects of wide range of rock and fluid properties on IPR for solution gas-drive reservoirs were studied using 3D radial single well simulation models to generate a general IPR correlation that functions of the highly sensitive rock and fluid data.

\section{Methodology:}

More than 500 combinations of rock and fluid properties were used to generate different IPRs. Non-linear regression was used to get one distinct parameter representing each IPR. Then a non-parametric regression was used to generate the general IPR correlation. The generated IPR correlation was tested on nine synthetic and three field cases.

\section{Results \& Conclusion:}

The results showed the high application range of the proposed correlation compared to others that failed to predict the IPR. Moreover, the proposed correlation has an advantage that it is explicitly function of rock and fluid properties that vary per each reservoir.

Keywords: Inflow Performance Relationship (IPR), Analytical and empirical correlations, Solution gas-drive reservoirs, 3D radial single well simulation models, Non-linear regression, Non-parametric regression.

\section{INTRODUCTION}

Predicting the relationship between the flow rate and the pressure drop performance in the reservoir is very important for continuous production optimization. IPR curve can be combined with tubing performance curve to monitor well productivity, designing production and artificial lift equipment and to choose the proper remedial treatment options (acidizing, fracturing, work over, etc.) for optimum well performance.

\footnotetext{
* Address correspondence to this author at the Department of Petroleum Engineering, Cairo University, Giza, Egypt; Tel: +965-972-59268; E-mails: adawood@slb.com; a_daoud_72@yahoo.com
} 
In calculating oil production, it was assumed that an oil production rate is directly proportional to draw down. Using this assumption, well's behavior can be described by productivity index; PI. This PI relationship was developed from Darcy's law for steady state radial flow of a single incompressible fluid.

$$
q=J(P e-P w f)
$$

Evinger and Muskat [1] pointed that the above relationship is not valid for two phase flow.

The first presentation of an inflow performance relationship (IPR) was made by Rawlins and Schellhardt [2]. They used their plot to show the effect of liquid loading on the production performance of gas wells. Gilbert [3] introduced the concept of an "Inflow Performance Relationship" (IPR).

Based on our literature survey, the different IPR correlations can be divided into empirically-derived and analytically-derived correlations.

\subsection{The empirically derived correlations are:}

- Vogel [4]

- Fetkovich [5]

- Jones et al. [6]

- Richardson and Shaw [7]

- Wiggins $[8,9]$

- Klins and Majcher [10]

- Sukarno and Wisnogroho [11]

\subsection{The Analytical correlations are:}

- Wiggins et al. $[8,12]$

- Del Castillo et al. $[13,14]$

Detailed description of all the above IPR models is given on Abdel Salam [15].

Different attempts afterwards were used to either give theoretical explanations of the above IPR correlations or to introduce modifications to the above IPR correlations. Examples of these attempts are as follows:

In 2007, Haiquan et al. [16] deduced a dimensionless IPR for a single phase (oil or gas), based on the nonlinear flow mathematical model developed by Forcheimer. This IPR for solution gas-drive reservoirs $\left(\mathrm{P}_{\mathrm{r}} \leq \mathrm{P}_{\mathrm{b}}\right)$ as well as partial solution gas- drive reservoirs $\left(\mathrm{P}_{\mathrm{r}} \geq \mathrm{P}_{\mathrm{b}}\right.$ and $\left.\mathrm{P}_{\mathrm{wf}} \leq \mathrm{P}_{\mathrm{b}}\right)$, developed by recognizing the similarity of deliverability equations between laminar flow and nonlinear (turbulent) flow of a single phase, and a general dimensionless IPR formula is gained by summing up and normalizing the IPRs in different cases as shown below where the characteristic parameters (a) and (n) have explicit physical significance.

$$
\left(\frac{p_{w f}}{p_{r}}\right)^{n}=1-a\left[\frac{q_{o}}{q_{o \max }}\right]-(1-a)\left[\frac{q_{o}}{q_{o \max }}\right]^{2}
$$

The parameter (n) describes the average extent of solution gas-drive. If $\mathrm{n}=1, \mathbf{E q} . \mathbf{2}$ is the dimensionless IPR for single phase oil flow (without solution gas-drive); $\mathrm{n}=2$, dimensionless IPR for single phase gas flow or oil flow by solution gas-drive; and $1<\mathrm{n}<2$, dimensionless IPR for partial solution gas-drive. The parameter (a) describes the type of flow where for $\mathrm{a}=1$, the flow is considered of laminar flow.

Ilk et al. [17] provided the analytical development of "Vogel"-type Inflow Performance Relationship correlations for solution gas-drive reservoir systems by proposing a characteristic mobility function that extended Del Castillo and Archer et al. $[13,14]$ work for assuming a polynomial mobility profile rather than the linear profile.

In 2009, Jahanbani and Shadizadeh [18] presented analytical solution for determination of IPR curves of oil wells below the bubble point pressure. This approach uses the results of well test analysis along with relative permeability and PVT data using the analytically derived flow equation in both transient and pseudo steady state.

Elias et al. [19] extended the Del Castillo and Archer et al. $[13,14]$ mobility equation as function of pressure and 
generated an empirical mobility ratio equation based on 47 field cases.

In 2012, Khasanov et al. [20] studied the effect of change in relative permeability and hence the mobility on the shape of the IPR using single well reservoir simulation models. They showed that Fetkovich Equation can be a good representation of the deliverability equation especially in the transition zone where the $P_{w f}$ is slightly lower than the $P_{b}$ and the shape of $\mathrm{K}_{\mathrm{rg}}$ is not increasing sharply with increase in gas saturation. Khasanov et al. [20] proposed a generic IPR correlation close to Fetkovich equation as follows:

$$
\frac{q_{o}}{q_{o \max }}=\left[1-\left[\frac{P_{w f}}{P_{r}}\right]^{m_{k}}\right]^{n_{k}}
$$

Where $\mathrm{m}_{\mathrm{k}}$ ranges from 1.4 to 2 with value of 2 being noticed when the $\mathrm{P}_{\mathrm{wf}}$ is close to $\mathrm{P}_{\mathrm{b}}$ and $\mathrm{K}_{\mathrm{rg}}$ is not increasing sharply with increase in gas saturation with $\mathrm{K}_{\mathrm{rg} \max }$ value being less than 0.05 . The $\mathrm{n}_{\mathrm{k}}$ values range from 0.75 to 1 with low values occurring in the transition zone during the depletion process where the $P_{w f}$ is slightly lower than the $P_{b}$ with low gas saturation and $n_{k}$ value tends to be1 when the reservoir pressure and the $P_{w f}$ are far below the $P_{b}$.

Through time IPR curves have used in different applications, Brown [21] in 1982 used IPR combined with tubing intake curves to provide an optimum artificial lift method to produce the well. In 1988, Avery and Evans [22] utilize IPR curves in examining the well performance under different artificial lift designs. IPR curves were also used during enhanced oil recovery process where Yeu et al. [23] in 1997 used IPR to predict the performance of an oil well under the implementation of polymer flooding. After emerging of the multi-lateral technology, Guo et al. [24] in 2006 derived composite IPR for multi-lateral wells. These are few of the many applications of IPR in oil industry.

Most of the IPR correlations suffer from common limitations that they are not explicitly function of the different reservoir rock and fluid properties that vary from one reservoir to another or its difficulty to be applied. This will affect the accuracy of the correlations especially if the reservoir properties of the well under study are completely different from the properties used in generating these correlations. In this work, a single well 3D radial reservoir model with solution gas-drive as the main driving mechanism was built and reservoir simulation was used to generate different IPRs by changing the reservoir rock and fluid properties. The most sensitive reservoir rock and fluid properties were selected to generate the new IPR correlation. This new correlation is based on generating 550 combination of the selected reservoir rock and fluid properties and run the simulation models to generate different 550 IPR curves. Then, the non-parametric regression technique was used to generate the new IPR correlation that is explicitly function of the reservoir rock and fluid properties that highly affect the IPR curve.

The outline of the paper is as follows. Firstly, we presented the assumptions we used in generating the single well reservoir simulation model. Secondly, we studied the sensitivity of the IPR towards different rock and fluid parameters to choose the highly sensitive parameters to be used in the IPR correlation. Thirdly, we presented the nonlinear and non-parametric regression techniques we used to develop the IPR correlation that is explicitly function of reservoir rock and fluid properties. Finally, we presented the validation of the new correlation based on different synthetic and field cases.

\section{MODEL CONSTRUCTION}

MORE [25] that stands for Modular Oil Reservoir Evaluation was used to simulate the multi-rate test for constructing the IPR curve. The reservoir simulator was used to construct 550 reservoir models that cover a wide range of rock and fluid properties. These different reservoir models were used to examine the sensitivity of IPR curve towards the change in the reservoir rock and fluid properties, to select the highly sensitive properties for developing the IPR correlation. It is important to mention here that in constructing the single well reservoir simulation model, all the points on the IPR curve were in the pseudo-steady flow period with constant rate at the inner boundary and no flow at the outer boundary with two phases flowing which were oil and gas. The general assumptions used in building the reservoir models can be summarized as follows:

- 3D radial flow into the well bore as shown in Fig. (1).

- The reservoir initially at the bubble point pressure

- Vertical well at the center of the formation.

- The well is completed through the whole formation thickness. 
- Homogeneous, bounded reservoir (Pseudo steady state flow period).

- Isothermal conditions exist

- Two Phase Flow (Oil \& Gas).

- Capillary pressure is neglected

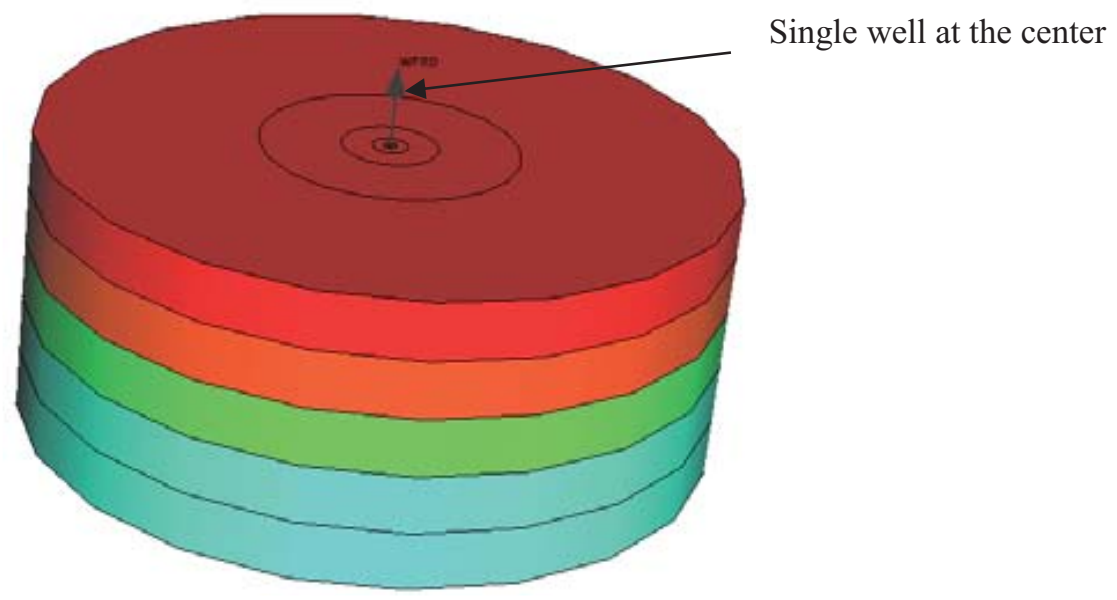

Fig. (1). 3D radial Model.

\section{SENSITIVITY ANALYSIS}

The sensitivity analysis is performed to examine the effect of different reservoir rock and fluid properties on the IPR behavior and hence selecting the highly sensitive parameters to be used in generating the IPR correlation.

Table (1) gives the range of reservoir rock and fluid properties used in this study. In the sensitivity analysis, one parameter was changed at a time while the rest was kept at its base value to be able to identify the sensitive parameters to the shape of the IPR curve.

Different rock and fluid properties are included in this study and the following list gives the properties that were found to have major effect on the IPR behavior using both IPR and dimensionless IPR plots:

Bubble Point Pressure, $\mathrm{P}_{\mathrm{b}}$

Reservoir Depletion Ratio $\left(\mathrm{P}_{\mathrm{r}} / \mathrm{P}_{\mathrm{b}}\right)$

Critical Gas Saturation, $\mathrm{S}_{\text {gcr }}$

Residual Oil Saturation in Gas, $\mathrm{S}_{\text {org }}$

Relative Permeability to Oil at $\mathrm{S}_{\mathrm{wcr}}, \mathrm{K}_{\text {row }}$ at $\left(\mathrm{S}_{\mathrm{wcr}}\right)$

Relative Permeability to Gas at $\left(1-\mathrm{S}_{\mathrm{wcr}}-\mathrm{S}_{\text {org }}\right), \mathrm{K}_{\mathrm{rg}}$ at $\left(1-\mathrm{S}_{\mathrm{wcr}}-\mathrm{S}_{\mathrm{org}}\right)$

Oil-Gas Relative Permeability Exponent, OGEXP

Gas Relative Permeability Exponent, GEXP

Skin, S

Figs. (2 to 19) show the IPR and dimensionless IPR behavior under the effect of the above mentioned rock and fluid properties that affect the IPR.

Table 1. Range of data used in the construction of the Proposed IPR Correlation.

\begin{tabular}{|c|c|c|}
\hline Rock/Fluid Property & Range & Units \\
\hline $\begin{array}{c}\text { Initial Reservoir Pressure } \\
\text { (Bubble point pressure) }\end{array}$ & $1451-5413$ \\
\hline Reservoir Depletion Ratio $\left(\mathrm{P}_{\mathrm{r}} / \mathrm{P}_{\mathrm{b}}\right)$ & $0.33-0.95$ & dimensionless \\
\hline Reservoir Temperature & $100-400$ & ${ }^{\circ} \mathrm{F}$ \\
\hline Oil Gravity & $0.7-0.85$ & dimensionless \\
\hline
\end{tabular}




\begin{tabular}{|c|c|c|}
\hline Rock/Fluid Property & Range & Units \\
\hline Gas Gravity & $0.5-1.2$ & dimensionless \\
\hline Water Gravity & $1.0-1.25$ & dimensionless \\
\hline Water Viscosity & $0.1-1.0$ & $\mathrm{cp}$ \\
\hline $\mathrm{R}_{\mathrm{s}}$ & $0.47-2.16$ & Mscf/stb \\
\hline $\mathrm{B}_{\mathrm{o}}$ & $1.12-2.52$ & $\mathrm{bbl} / \mathrm{stb}$ \\
\hline$\mu_{\mathrm{o}}$ & $0.09-0.44$ & $\mathrm{cp}$ \\
\hline $\mathrm{Z}$ (Gas Deviation Factor) & $0.7-1.042$ & dimensionless \\
\hline $\mathrm{S}_{\mathrm{wcr}}$ & $0-0.3$ & fraction \\
\hline $\mathrm{S}_{\mathrm{gcr}}$ & $0-0.3$ & fraction \\
\hline $\mathrm{S}_{\text {orw }}$ & $0-0.6$ & fraction \\
\hline $\mathrm{S}_{\mathrm{org}}$ & $0-0.4$ & fraction \\
\hline OGEXP ( $\mathrm{K}_{\mathrm{rog}}$ Exponent) & $1-5$ & dimensionless \\
\hline OWEXP ( $\mathrm{K}_{\text {row }}$ Exponent $)$ & $1-7$ & dimensionless \\
\hline WEXP ( $\mathrm{K}_{\mathrm{rw}}$ Exponent) & $2-8$ & dimensionless \\
\hline GEXP ( $\mathrm{K}_{\mathrm{rg}}$ Exponent) & $1-7$ & dimensionless \\
\hline $\mathrm{K}_{\mathrm{rw} \text { at }}\left(\mathrm{S}_{\text {orw }}\right)$ & $0.2-1.0$ & fraction \\
\hline $\mathrm{K}_{\text {row at }}\left(\mathrm{S}_{\mathrm{wcr}}\right)$ & $0.2-1.0$ & fraction \\
\hline $\mathrm{K}_{\mathrm{rg} \mathrm{at}}\left(1-\mathrm{S}_{\text {wcr }}-\mathrm{S}_{\text {org }}\right)$ & $0.4-1.0$ & fraction \\
\hline Drainage Radius & $100-10000$ & $\mathrm{ft}$ \\
\hline Thickness, $\mathrm{h}$ & $10-1000$ & $\mathrm{ft}$ \\
\hline $\mathrm{K}_{\mathrm{v}}$ & $0.5-500$ & $\mathrm{md}$ \\
\hline $\mathrm{K}_{\mathrm{h}}$ & $1-1000$ & $\mathrm{md}$ \\
\hline Skin & $(-6)$ to $(6)$ & dimensionless \\
\hline Porosity & $0.03-0.35$ & fraction \\
\hline
\end{tabular}

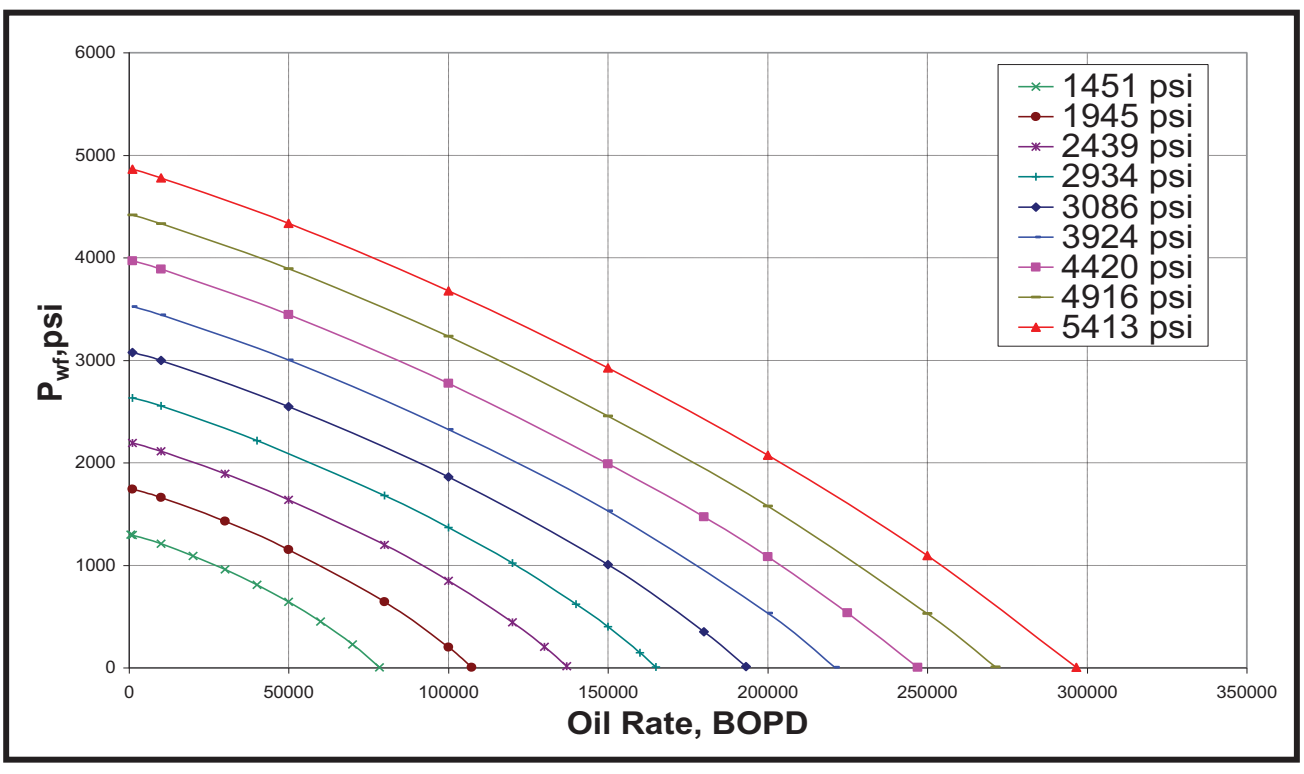

Fig. (2). Effect of Bubble Point Pressure on the IPR curve. 


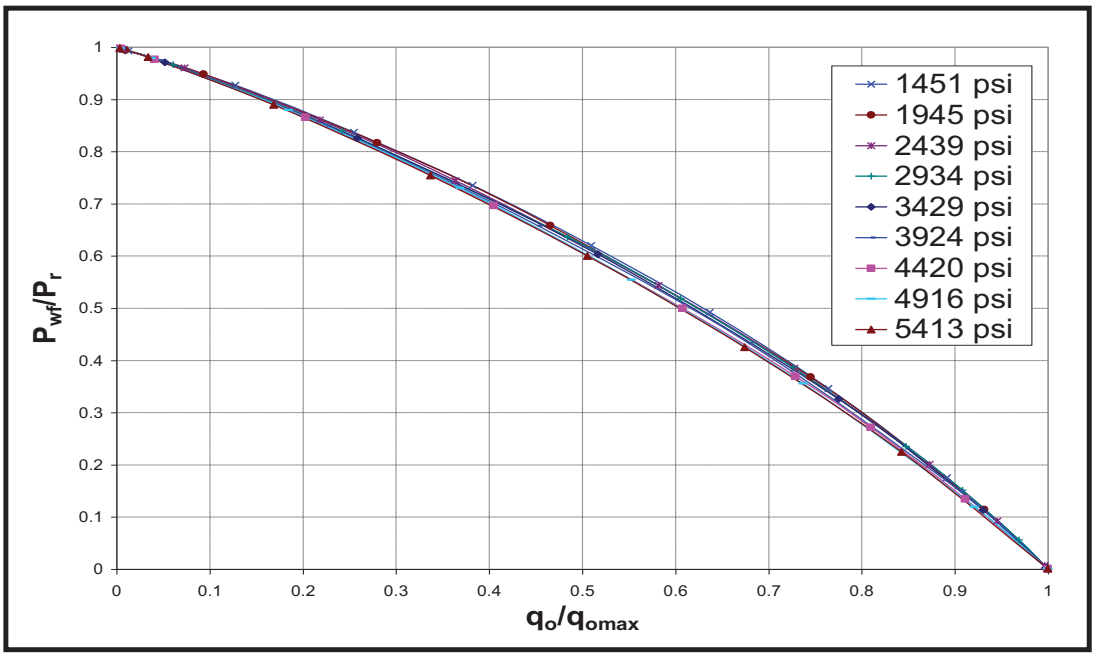

Fig. (3). Effect of Bubble Point Pressure on the dimensionless IPR curve.

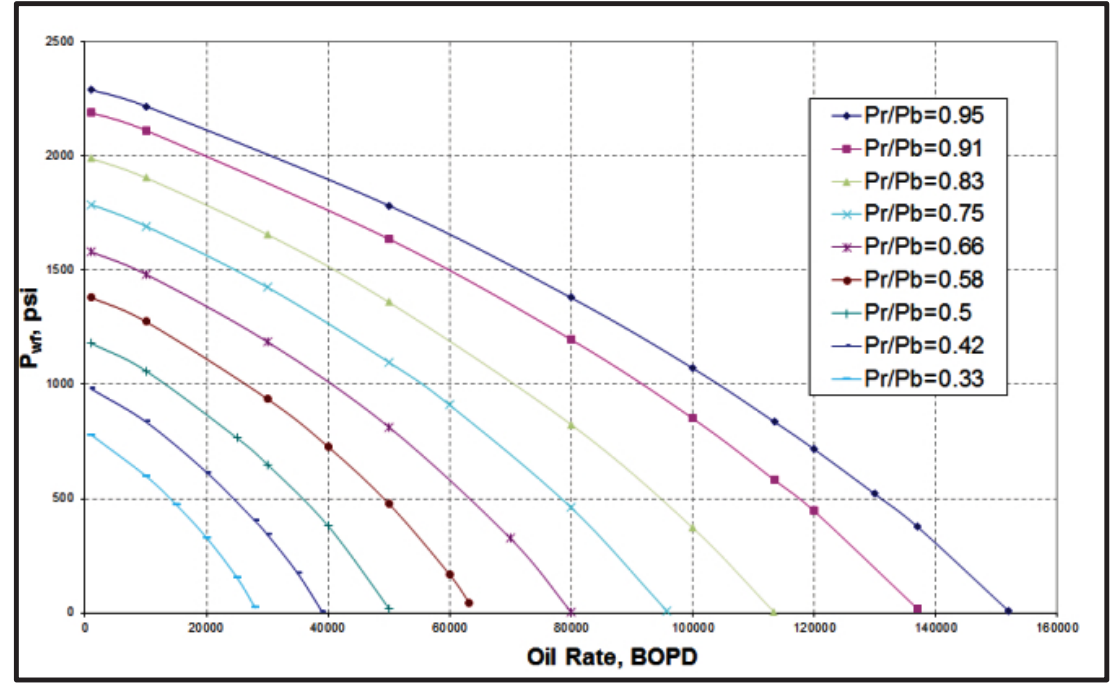

Fig. (4). Effect of Reservoir Pressure Depletion on the IPR curve.

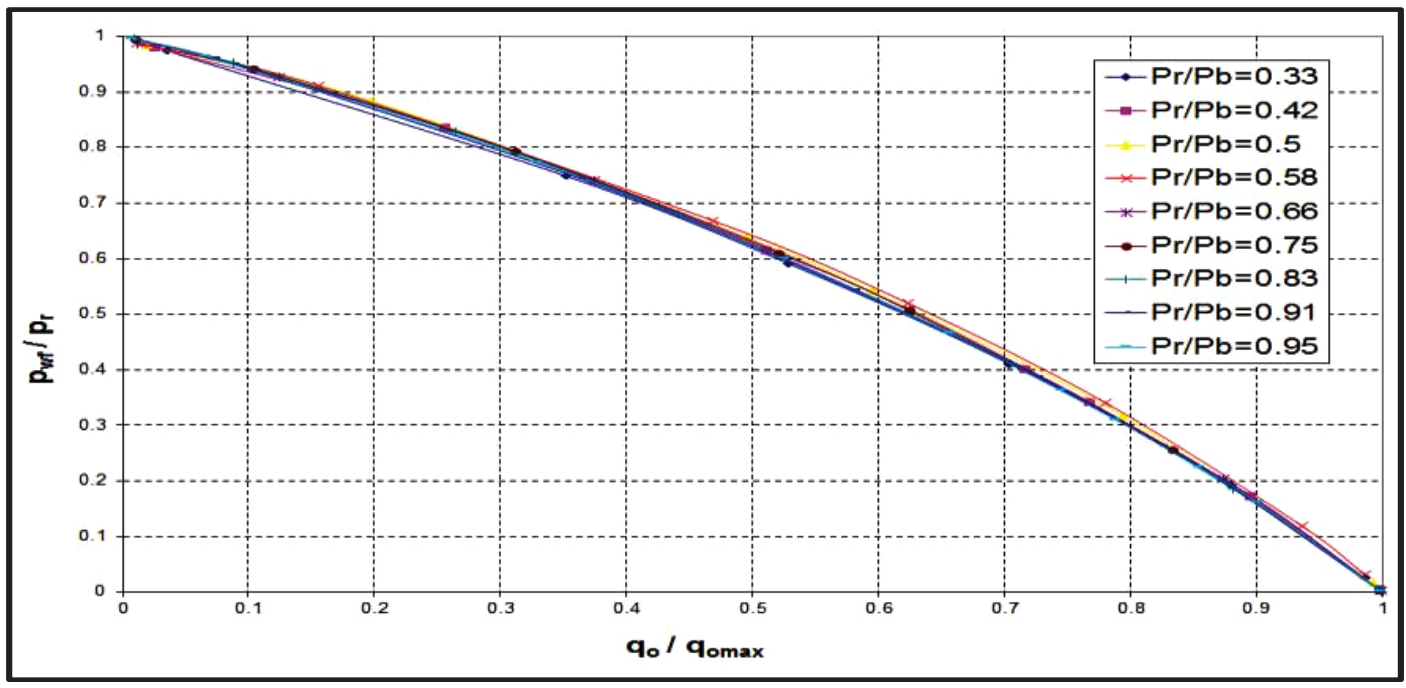

Fig. (5). Effect of Reservoir Pressure Depletion on the dimensionless IPR curve. 


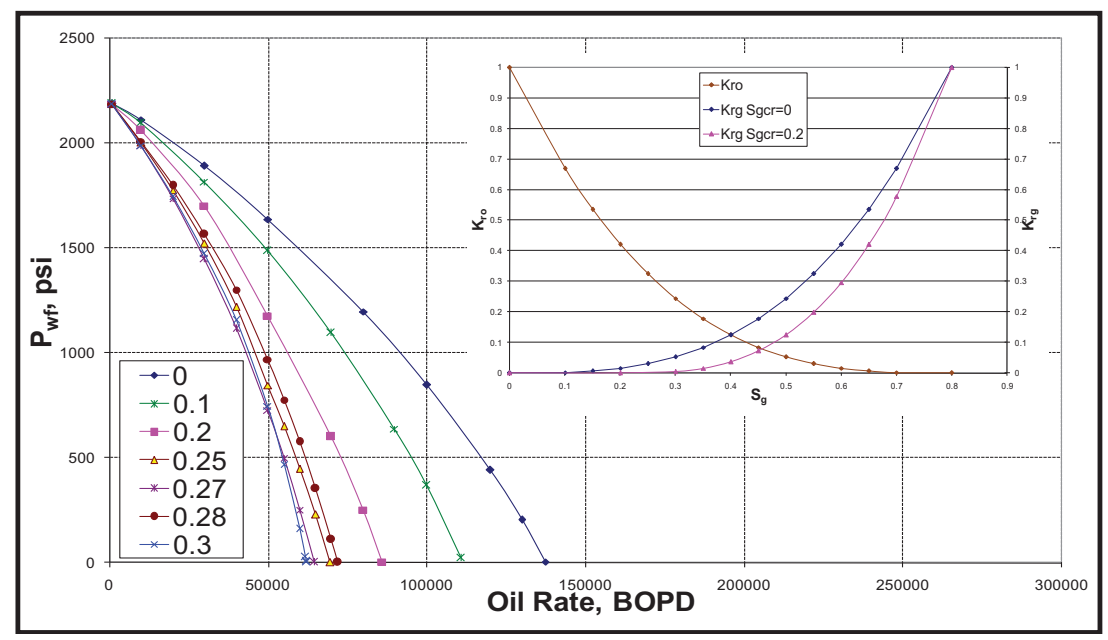

Fig. (6). Effect of $\mathrm{S}_{\text {gcr }}$ on the IPR curve.

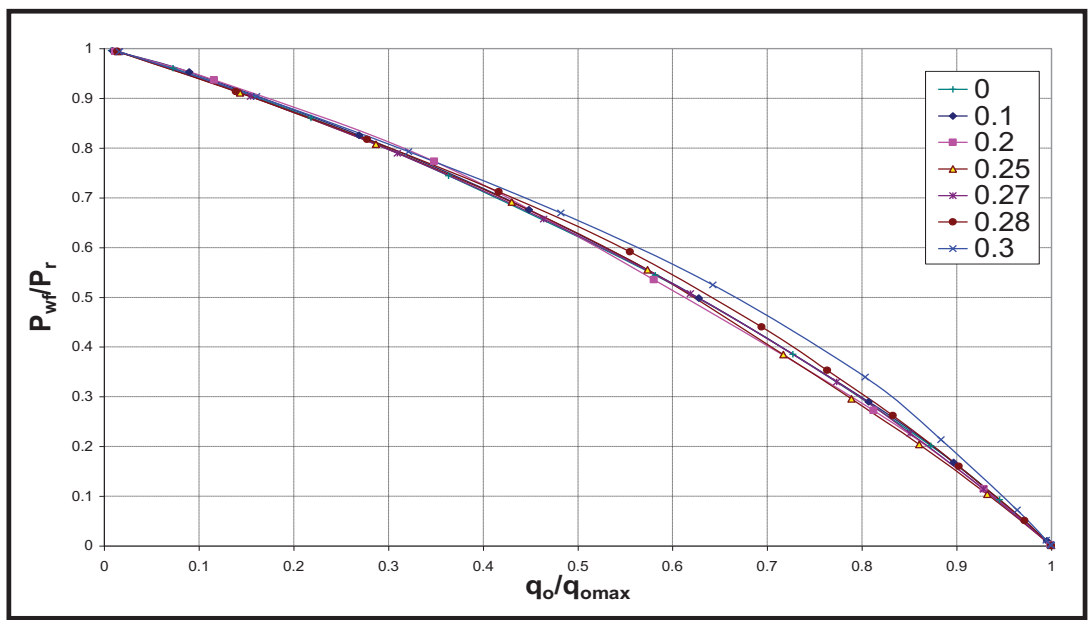

Fig. (7). Effect of $\mathrm{S}_{\text {gcr }}$ on the dimensionless IPR curve.

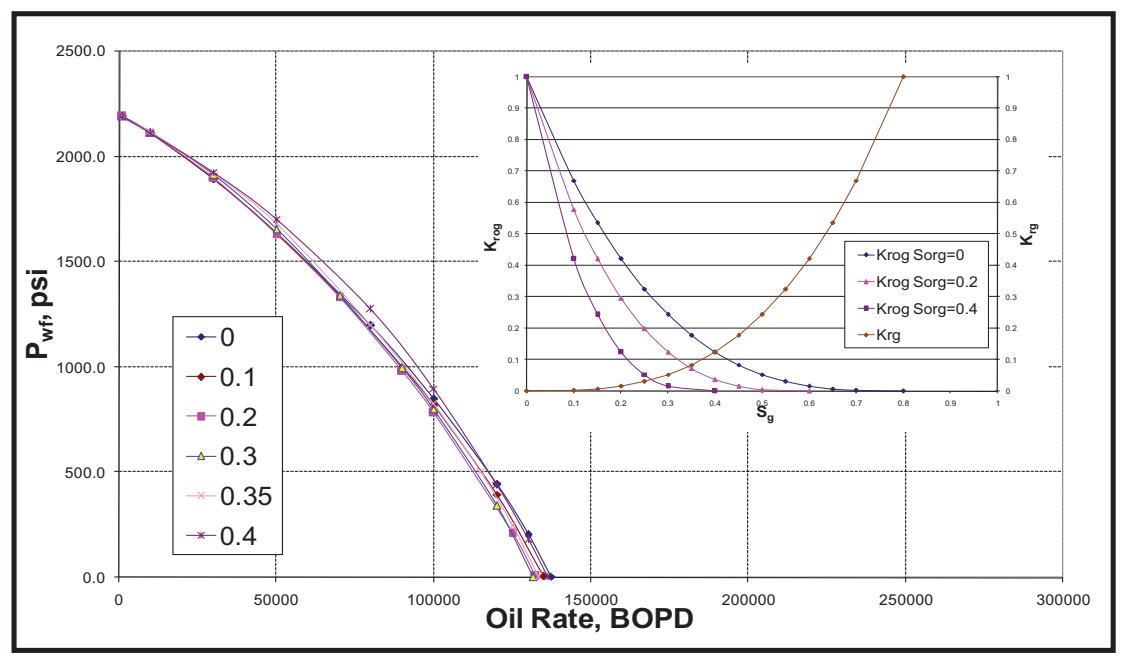

Fig. (8). Effect of $S_{\text {org }}$ on the IPR curve. 


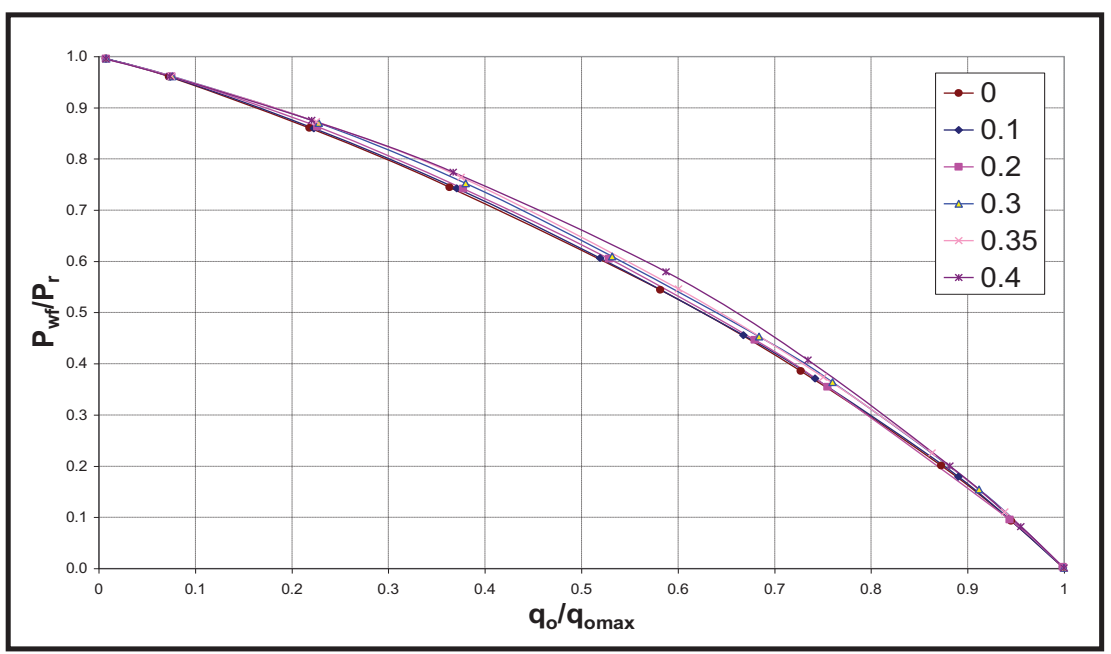

Fig. (9). Effect of $\mathrm{S}_{\text {org }}$ on the dimensionless IPR curve.

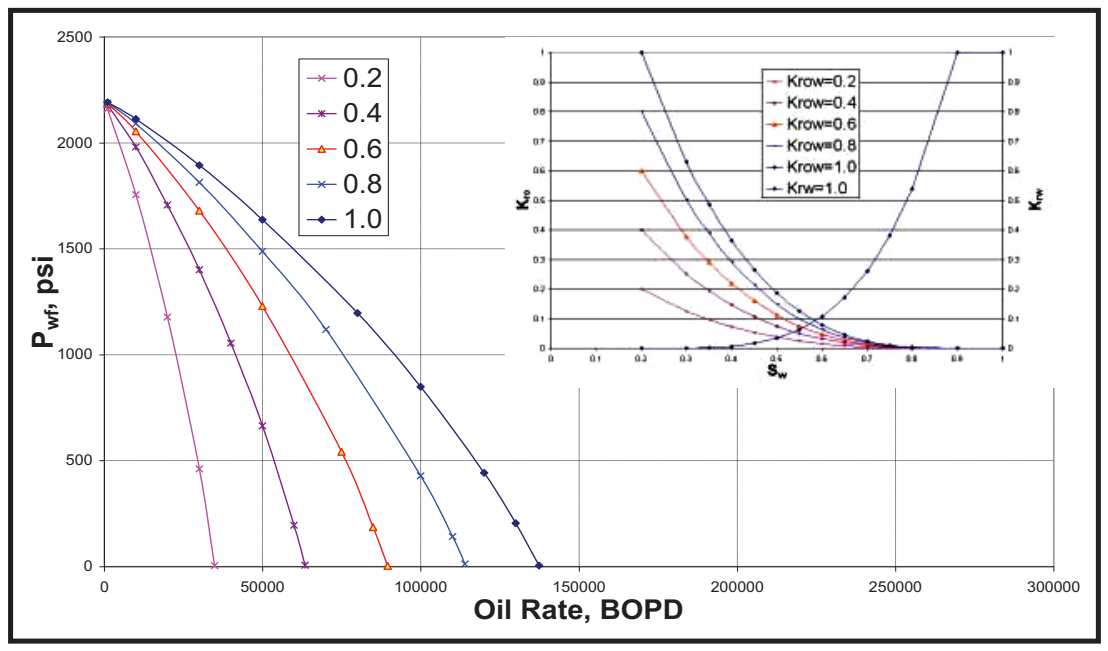

Fig. (10). Effect of $K_{\text {row }}$ at $\left(S_{\text {wcr }}\right)$ on the IPR curve.

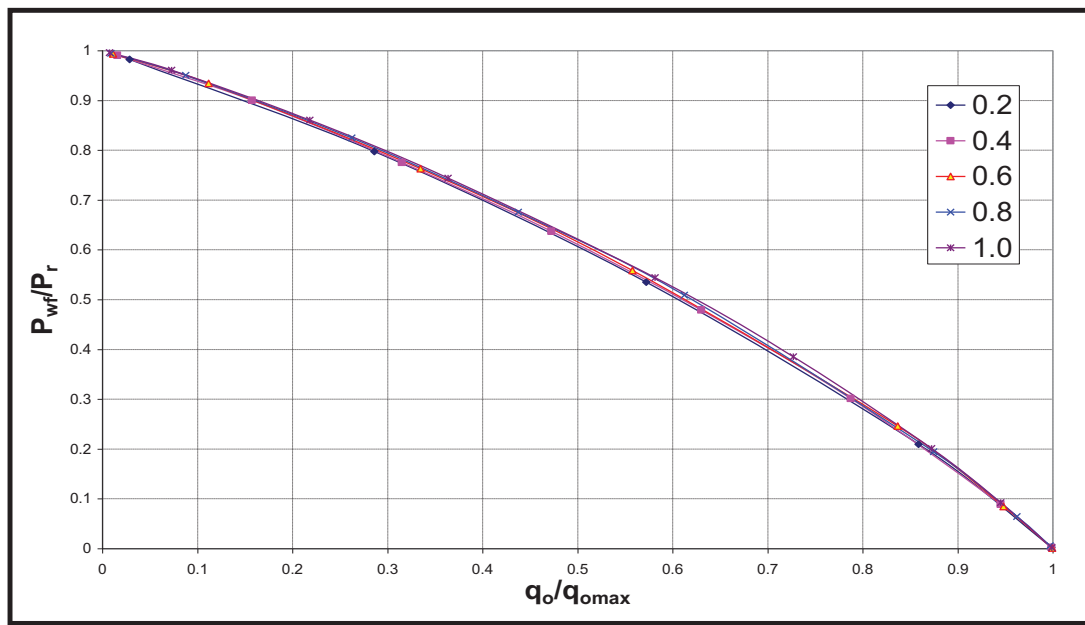

Fig. (11). Effect of $K_{\text {row }}$ at $\left(S_{\text {wcr }}\right)$ on the dimensionless IPR curve. 


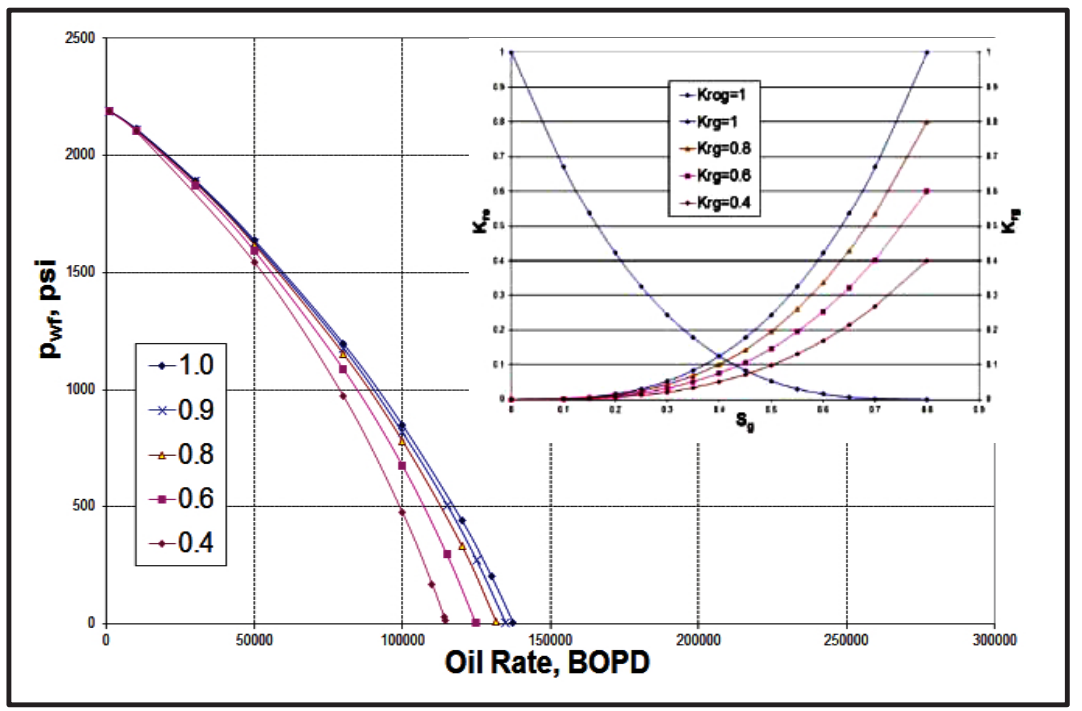

Fig. (12). Effect of $K_{r g}$ at $\left(1-S_{w c r}-S_{\text {org }}\right)$ on the IPR curve.

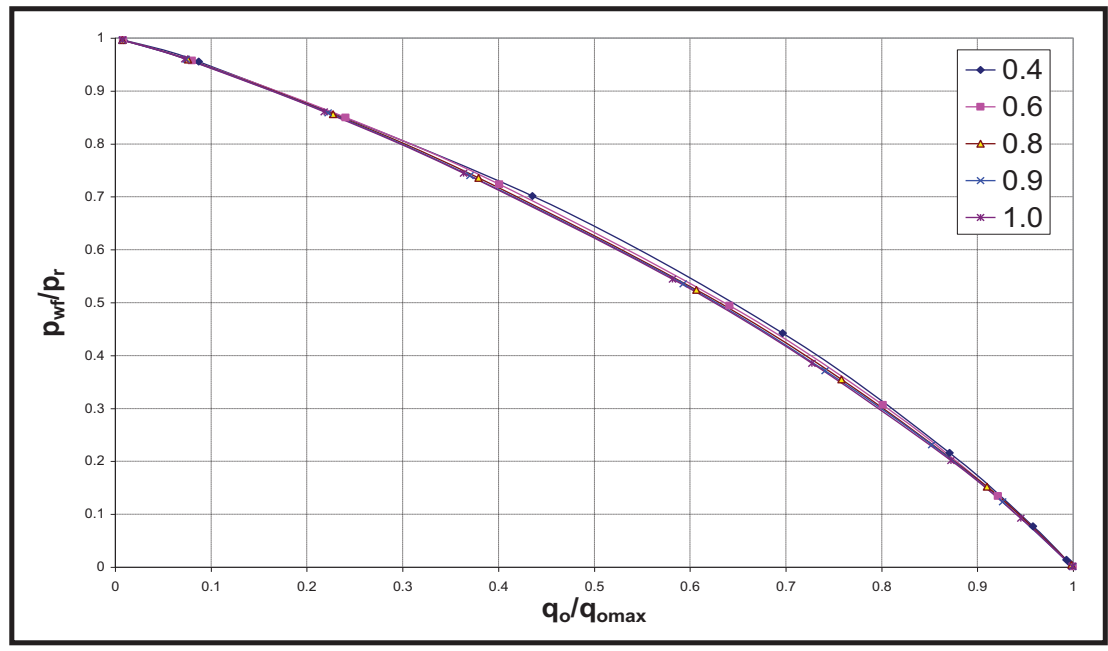

Fig. (13). Effect of $\mathrm{K}_{\mathrm{rg}}$ at $\left(1-\mathrm{S}_{\mathrm{wcr}}-\mathrm{S}_{\mathrm{org}}\right)$ on the dimensionless IPR curve.

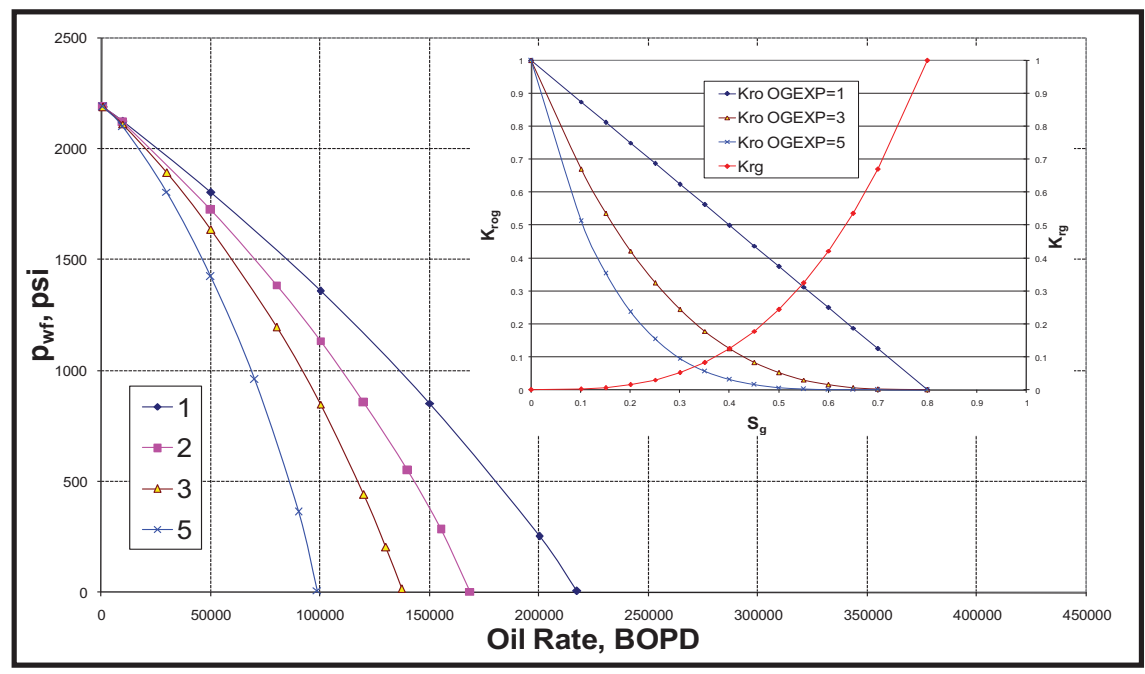

Fig. (14). Effect of OG Exponent on the IPR curve. 


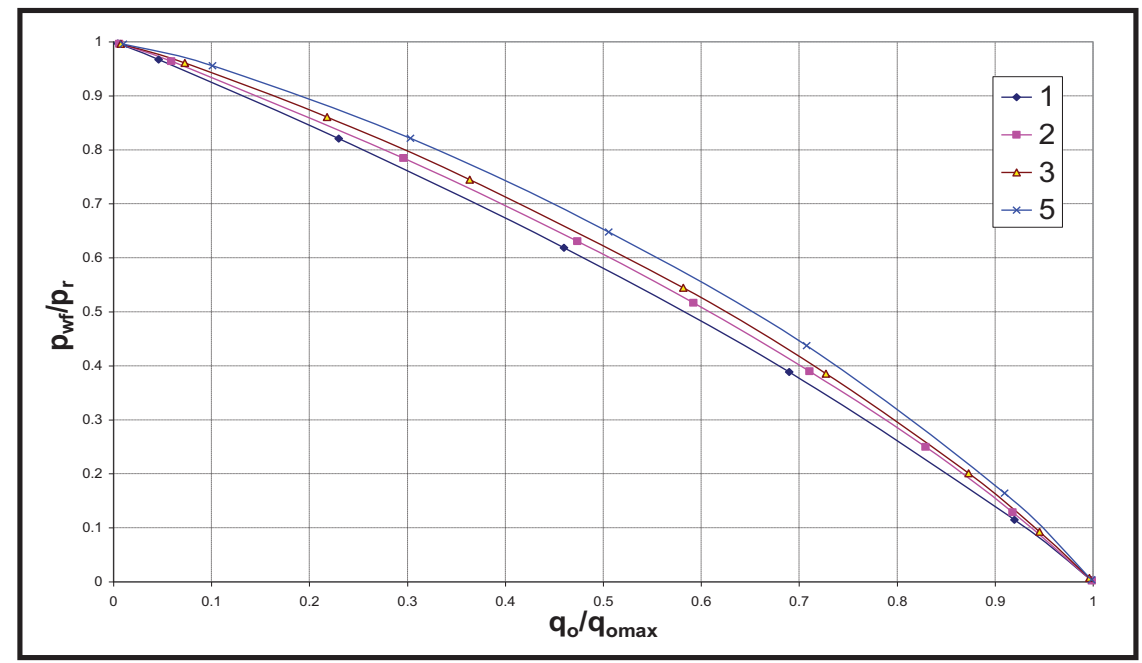

Fig. (15). Effect of OG Exponent on the dimensionless IPR curve.

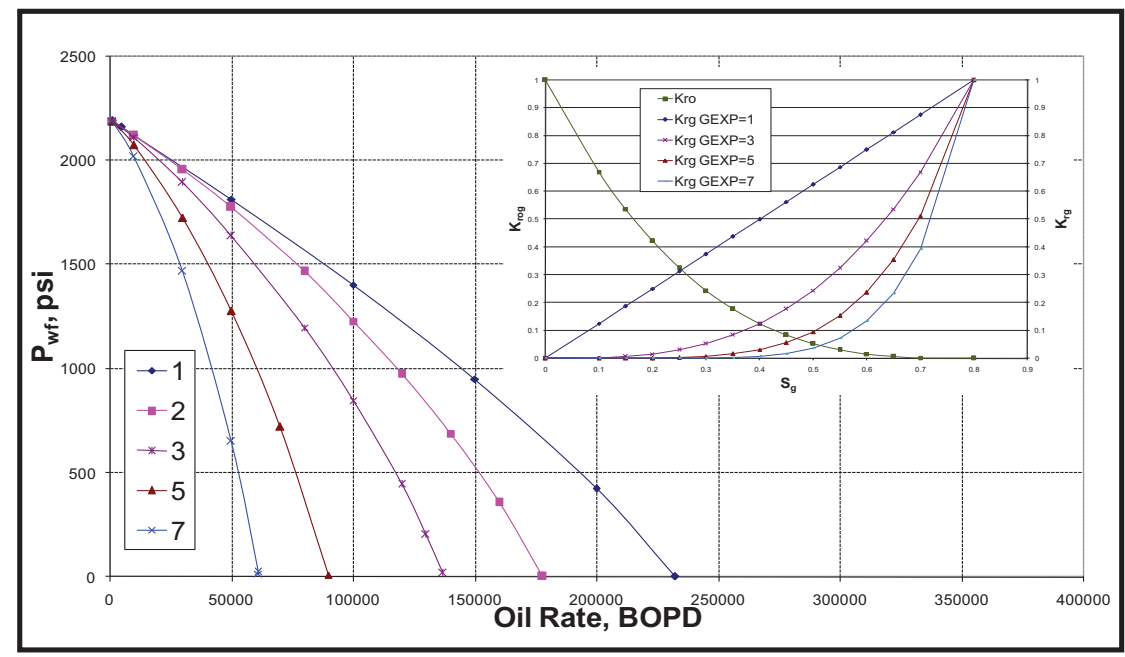

Fig. (16). Effect of Gas Exponent on the IPR curve.

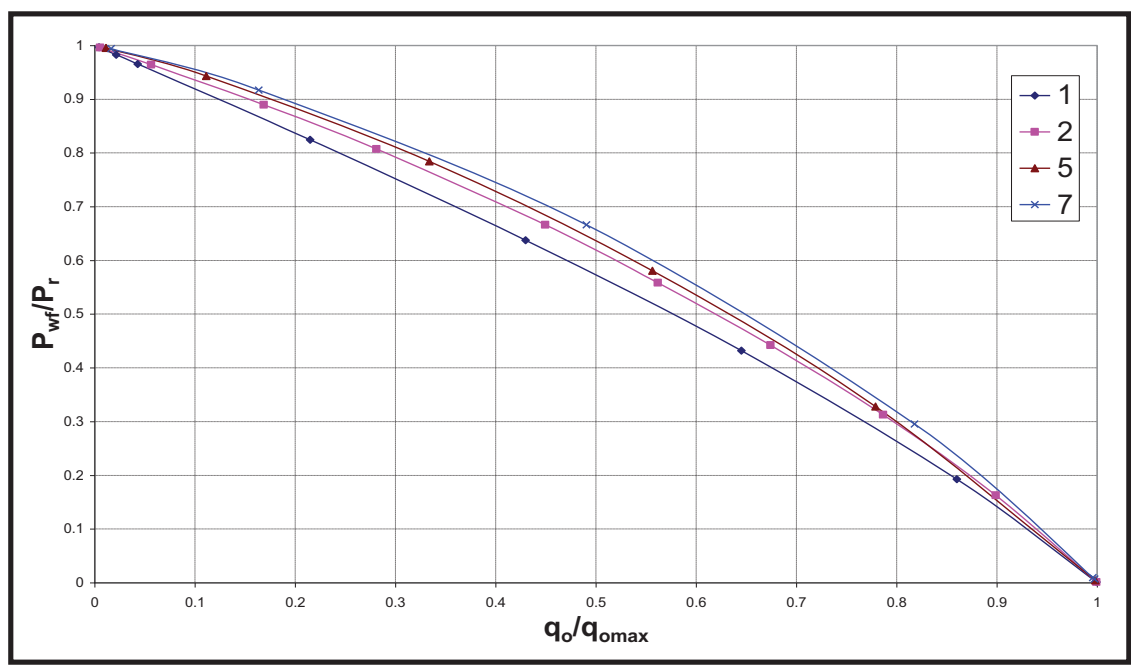

Fig. (17). Effect of Gas Exponent on the dimensionless IPR curve. 


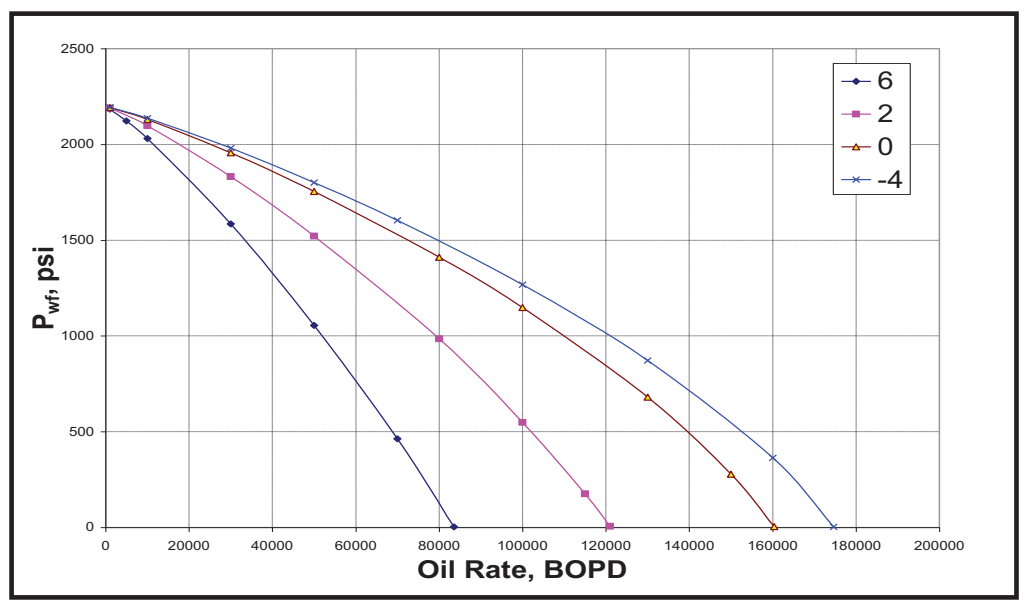

Fig. (18). Effect of Skin on the IPR curve.

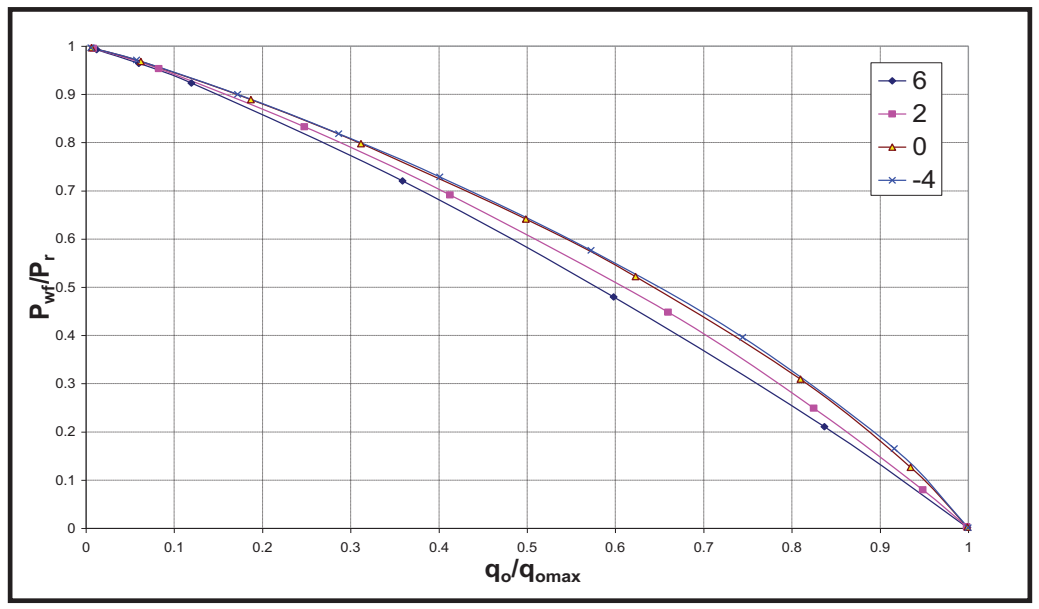

Fig. (19). Effect of Skin on the dimensionless IPR curve.

The IPR and the dimensionless IPR performance was found insensitive to all the parameters that are mainly affecting the water flow in the reservoir, as the assumption used in this study is solution gas- drive reservoir with minimum water flow. This is in addition to the other parameters that has less effect on the oil and gas flow.

\subsection{The following list gives the properties that found did not affect the IPR behavior:}

1. Water Gravity, $\gamma_{W}$

2. Water Viscosity, $\mu_{W}$

3. Critical water saturation, $S_{w c r}$

4. Residual oil saturation in Water, $\mathrm{S}_{\text {orw }}$

5. Relative permeability to water at $\mathrm{S}_{\text {orw }}, \mathrm{K}_{\mathrm{rw}}$ at $\left(\mathrm{S}_{\mathrm{orw}}\right)$

6. Oil-Water relative permeability exponent, OWEXP

7. Water relative permeability exponent, WEXP

8. Porosity

3.2. The following list gives the properties that found did not affect the dimensionless IPR behavior:
1. Temperature
2. Oil gravity
3. Gas gravity
4. Vertical permeability
5. Horizontal permeability 
6. Drainage radius

7. Formation thickness

\subsection{Non-Parametric Regression Analysis}

550 IPRs were generated from the combination of the 9 sensitive parameters identified from the sensitivity analysis using simulation models. This was followed by implementing the non-linear regression technique to get the distinct parameter $\left(C_{1}\right)$ that represents each IPR based on Vogel [4] and Richardson and Shaw [7] correlations as shown below in Eq. 4:

$$
\frac{q_{o}}{q_{o \max }}=1-C_{1}\left[\frac{P_{w f}}{P_{r}}\right]-\left(1-C_{1}\right)\left[\frac{P_{w f}}{P_{r}}\right]^{2}
$$

The generated values for $\mathrm{C}_{1}$ corresponding to the 550 combinations of different rock and fluid properties represent the database used in generating the new IPR correlation.

In order to generate IPR correlation that is explicitly function of the different reservoir rock and fluid properties, we need to build a correlation between the $C_{1}$ (dependent variables) given in Eq. 4 and the 9 sensitive rock and fluid properties (independent variables) presented before. Since the formula that relates the dependent and independent variables is not known so parametric regression analysis cannot be implemented here which leads to the implementation of non-parametric regression analysis in our work. Neural Network modeling can be considered as one of the nonparametric modeling approaches and has wide range of applications in oil industry. However, the method that was used here is based on the Alternating Conditional Expectation (ACE) algorithm [26, 27]. A comparison between Neural Network and ACE algorithm was used to build bubble point pressure correlation for oil reservoirs [28] and it was found that the predictive strength of ACE is much higher compared to Neural Network for the studied samples. The ACE algorithm is based on the concept of developing non-parametric transformations of the dependent and independent variables. Moreover, the transformations are constructed point wise based only on the data without the need to know a prior function between the dependent and independent variables. The final correlation is given by plotting the transformed dependent variable against the sum of the transformed independent variables. The final result is a maximum correlation between the dependent and multiple independent variables with a minimum error. Fig. (20) shows the relationship between the transformed dependent variable $C_{1}$ versus the sum of the transformed independent variables that gives the highest correlation coefficient. The optimal regression correlation here is $\mathbf{0 . 9 1 7 7 5}$ as shown in Fig. (20).

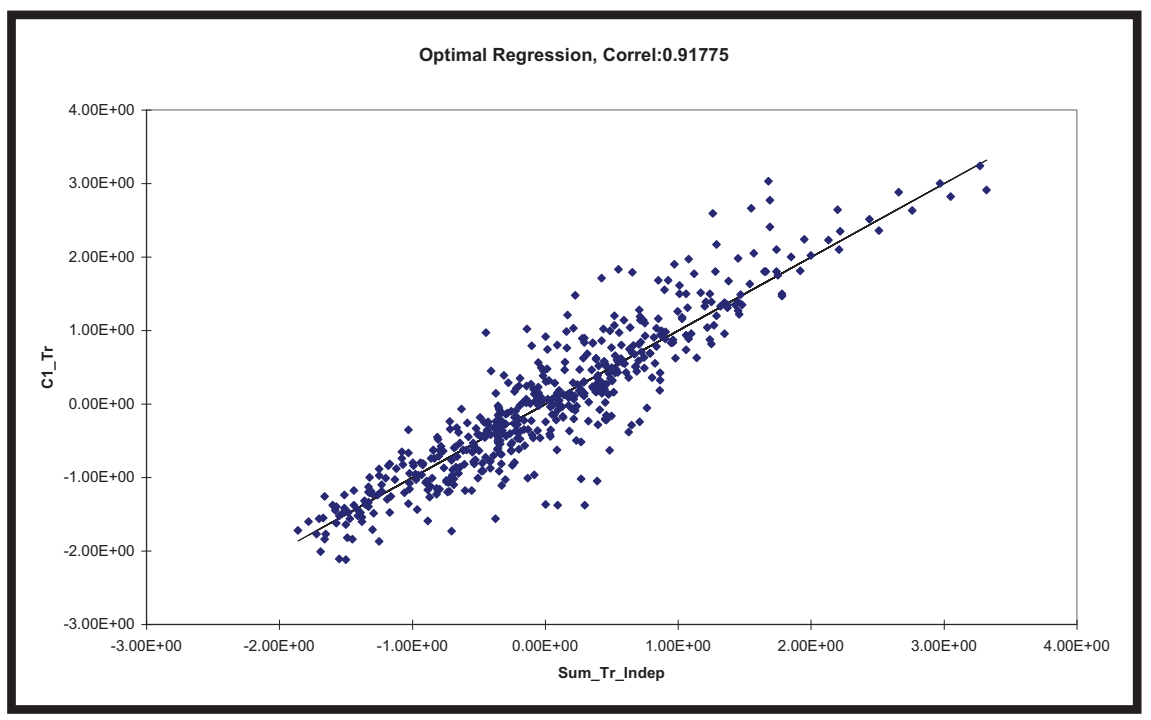

Fig. (20). Transformed dependent variable vs. sum of the transformed independent variables.

The 550 several combinations of the 9 sensitive parameters which represent the independent variables with one dependent variable that is $\mathrm{C}_{1}$ were used in the ACE Algorithm [27] to find the best correlation between the dependent and the independent variables. The resulted IPR correlation is given in Eq. 4 with $\mathrm{C}_{1}$ as explicit polynomial function of 
different reservoir rock and fluid properties which is given as follows:

$$
C_{1}=-0.012(A)^{2}+0.161(A)+0.517
$$

Where, the independent variable $(\mathrm{A})$ is given as:

$$
\begin{aligned}
& A=B+C+D+E+F+G+H+I+J \text { Where, } \\
& B=1.34\left(P_{r} / P_{b}\right)^{2}-1.326\left(P_{r} / P_{b}\right)+0.1 \\
& C=0.072(G E X P)^{2}-0.766(G E X P)+1.431 \\
& D=0.054\left(\left.K_{r g}\right|_{(1-\text { Swi-Sorg }}\right)^{2}+0.634\left(\left.K_{r g}\right|_{(1-\text { Swi-Sorg }}\right)-0.457 \\
& E=0.424\left(\left.K_{\text {row }}\right|_{S_{\text {wer }}}\right)^{2}-1.471\left(\left.K_{\text {row }}\right|_{S_{\text {wrr }}}\right)+0.793 \\
& F=0.083(\text { OGEXP })^{2}-0.816(\text { OGEXP })+1.487 \\
& G=4.812 \mathrm{E}-08\left(P_{b}\right)^{2}-2.28 \mathrm{E}-04\left(P_{b}\right)+0.225 \\
& H=-1.192\left(S_{\text {gcr }}\right)^{2}+2.421\left(S_{\text {gcr }}\right)-0.171 \\
& I=0.02(s)^{2}+0.202(s)-0.165 \\
& J=0.963\left(S_{\text {org }}\right)^{2}-1.351\left(S_{\text {org }}\right)+0.161
\end{aligned}
$$

Fig. (21) shows the comparison between the calculated and measured $C_{1}$ distinct IPR parameter from our reservoir parameters data base used in building the IPR correlation. This reflects the good accuracy of the correlation to accurately predict the IPR performance within our data base. At the same time, the variation of $\mathrm{C}_{1}$ from 0 to 1 reflects that the selected reservoir parameters used in building the IPR correlation cover wide range of reservoir rock and fluid properties which increase the range of application of the proposed IPR correlation compared to $C_{1}$ of 0.2 used by Vogel [4] correlation.

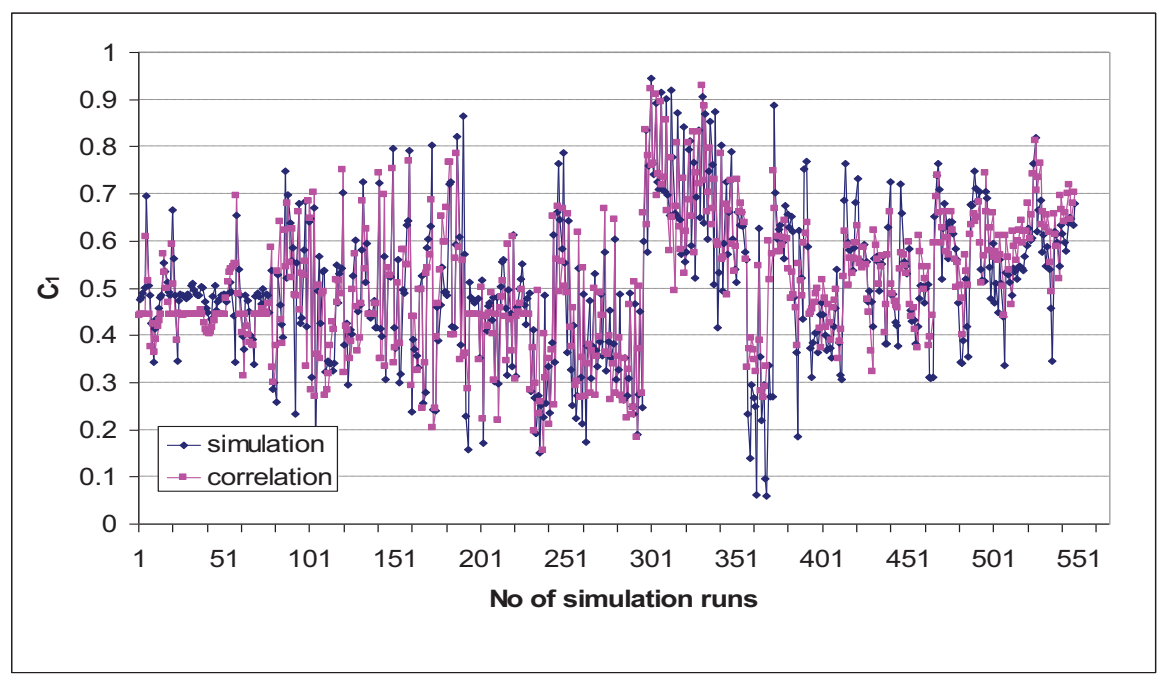

Fig. (21). $\mathrm{C}_{1}$ comparison; simulation versus proposed correlation for the data base cases. 


\section{VALIDATION}

\subsection{Synthetic Cases}

In order to test the performance of our proposed IPR correlation in accurately predicting the IPR performance, we generated nine different combinations of reservoir rock and fluid properties which are different from those used in our data base used in building the correlation, and then we used reservoir simulation model to generate the IPRs for these 9 different combinations. We used our proposed correlation with the nine different reservoir rock and fluid properties to estimate the distinct IPR parameter $\mathrm{C}_{1}$ which is then used to get the IPR performance per each reservoir and compare it with the actual IPR generated from the reservoir simulation. The proposed IPR correlation was able to successfully predict the true IPR with the least error compared to the other IPR models within errors range from 2.0 to $2.4 \%$. Fig. (22) shows the comparison between the actual $C_{1}$ generated from the reservoir simulation models with that calculated from the proposed IPR correlation from the data base cases and the nine validation cases (points in pink color). In addition, Figs. (23a and $\mathbf{b}$ ) and Tables (2a and $\mathbf{b})$ give the IPR comparison from 2 out of the 9 validation cases which show 2.4 and 2.3\% error respectively. As observed from Figs. (23a, and b) and Table (2a and b) our proposed correlation was able to accurately predict the IPR performance within an acceptable accuracy compared to the other correlations. In all these synthetic cases, the multi rate test data was taken at high draw down that can reach to more than $90 \%$ of the reservoir pressure which is practically difficult to be done in the field cases as will be shown later.

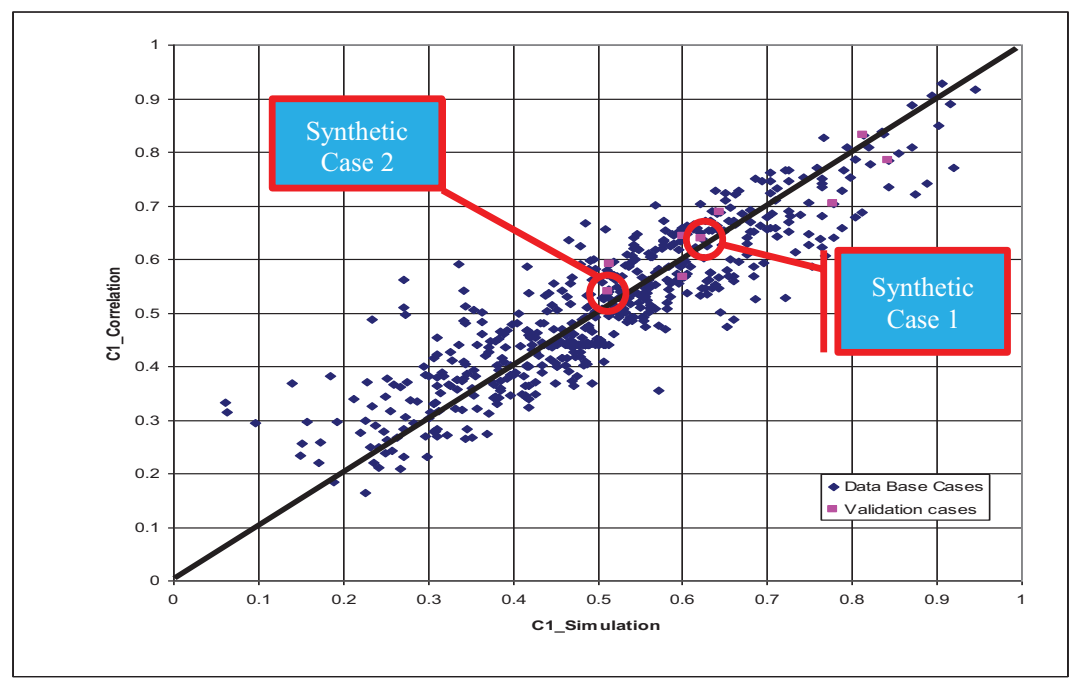

Fig. (22). Comparison of $C_{1}$ from the simulation models and the proposed correlation for the 550 data base cases and 9 synthetic cases.

Table 2a. Multi-rate test data and estimated flow rates for synthetic case 1.

\begin{tabular}{|c|c|c|c|c|c|c|c|c|c|c|}
\hline \multicolumn{2}{|c|}{ Multi rate Data } & \multirow{2}{*}{$\begin{array}{c}\begin{array}{c}\text { Proposed } \\
\text { Correlation }\end{array} \\
\mathbf{q}_{\mathrm{o}}(\mathbf{b b l} / \mathrm{day})\end{array}$} & \multirow{2}{*}{$\begin{array}{c}\text { Vogel } \\
\begin{array}{c}\mathbf{q}_{\mathrm{o}} \\
\text { (bbl/day) }\end{array}\end{array}$} & \multirow{2}{*}{\begin{tabular}{|l} 
Fetkovich \\
$q_{\text {o }}$ (bbl/day)
\end{tabular}} & \multirow{2}{*}{\begin{tabular}{|c|} 
Jones et al. \\
$\begin{array}{c}\mathbf{q}_{\mathrm{o}} \\
\text { (bbl/day) }\end{array}$ \\
\end{tabular}} & \multirow{2}{*}{$\begin{array}{c}\begin{array}{c}\text { Klins and } \\
\text { Majcher }\end{array} \\
\begin{array}{c}\mathbf{q}_{\mathbf{o}} \\
\text { (bbl/day) }\end{array}\end{array}$} & \multirow{2}{*}{$\begin{array}{c}\begin{array}{c}\text { Archer, Del } \\
\text { Castillo and } \\
\text { Blasingame }\end{array} \\
\begin{array}{c}\mathbf{q}_{\mathrm{o}} \\
\text { (bbl/day) }\end{array} \\
\end{array}$} & \multirow{2}{*}{$\begin{array}{c}\text { Wiggins } \\
\text { Empirical } \\
\text { Solution } \\
q_{0}(\text { bbl } / \text { day) }\end{array}$} & \multirow{2}{*}{$\begin{array}{c}\text { Wiggins } \\
\text { Analytical } \\
\text { Solution } \\
\mathbf{q}_{\mathbf{0}}(\mathbf{b b l} / \mathrm{day})\end{array}$} & \multirow{2}{*}{$\begin{array}{c}\begin{array}{c}\text { Sukarno and } \\
\text { Wisnogroho }\end{array} \\
\begin{array}{c}\mathbf{q}_{\mathrm{o}} \\
\text { (bbl/day) }\end{array}\end{array}$} \\
\hline $\begin{array}{r}P_{w f} \\
(p s i)\end{array}$ & $\begin{array}{c}\mathbf{q}_{\mathrm{o}} \\
\text { (bbl/day) }\end{array}$ & & & & & & & & & \\
\hline 2917 & 1000 & 1012 & 1058 & 906 & 994 & 1373 & 1040 & 1013 & 1014 & 1103 \\
\hline 2569 & $\begin{array}{l}5000 \\
\end{array}$ & 5066 & 5200 & 5000 & $\begin{array}{l}5000 \\
\end{array}$ & 6010 & 5148 & 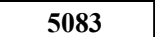 & 5082 & 5323 \\
\hline 2105 & 10000 & 10000 & 10000 & 10000 & 10000 & 10000 & 10000 & 10000 & 10000 & 10000 \\
\hline 1602 & 15000 & 14753 & 14282 & 14463 & 15070 & 12472 & 14465 & 14685 & 14598 & 13895 \\
\hline 1031 & 20000 & 19378 & 17963 & 18130 & 20444 & 14009 & 18512 & 19171 & 18760 & 16904 \\
\hline 321 & 25000 & 24016 & 20815 & 20506 & 26699 & 15227 & 22056 & 23543 & 22238 & 18788 \\
\hline 7 & 26550 & 25662 & 21459 & 20761 & 29321 & 15712 & 23089 & 25039 & 23133 & 19056 \\
\hline $\mathbf{0}$ & & 25699 & 21470 & 20762 & 29383 & 15724 & 23110 & 25072 & 23149 & 19059 \\
\hline \multicolumn{2}{|c|}{$\begin{array}{c}\text { Average absolute } \\
\text { errors }\end{array}$} & $2.4 \%$ & $10.1 \%$ & $12.4 \%$ & $4.1 \%$ & $30.7 \%$ & $7.1 \%$ & $3.5 \%$ & $6.0 \%$ & $15.5 \%$ \\
\hline
\end{tabular}


Table 2b. Multi-rate test data and estimated flow rates for synthetic case 2.

\begin{tabular}{|c|c|c|c|c|c|c|c|c|c|c|}
\hline \multicolumn{2}{|c|}{ Multi rate Data } & \multirow{2}{*}{$\begin{array}{c}\begin{array}{c}\text { Proposed } \\
\text { Correlation }\end{array} \\
\mathbf{q}_{\mathrm{o}}(\mathbf{b b l} / \mathrm{day})\end{array}$} & \multirow{2}{*}{ 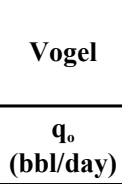 } & \multirow{2}{*}{\begin{tabular}{|l|} 
Fetkovich \\
$\mathbf{q}_{\mathrm{o}}$ (bbl/day) \\
\end{tabular}} & \multirow{2}{*}{$\begin{array}{c}\begin{array}{c}\text { Jones } e t \\
a l . .\end{array} \\
\begin{array}{c}\mathbf{q}_{\mathrm{o}} \\
\text { (bbl/day) }\end{array}\end{array}$} & \multirow{2}{*}{$\begin{array}{c}\begin{array}{c}\text { Klins and } \\
\text { Majcher }\end{array} \\
\mathbf{q}_{\mathrm{o}} \\
\text { (bbl/day) }\end{array}$} & \multirow{2}{*}{$\begin{array}{c}\text { Archer, Del } \\
\text { Castillo and } \\
\text { Blasingame } \\
q_{\mathrm{o}} \\
\text { (bbl/day) }\end{array}$} & \multirow{2}{*}{\begin{tabular}{|c}
$\begin{array}{c}\text { Wiggins } \\
\text { Empirical } \\
\text { Solution }\end{array}$ \\
$\mathbf{q}_{\mathrm{o}}$ (bbl/day)
\end{tabular}} & \multirow{2}{*}{\begin{tabular}{|c}
$\begin{array}{c}\text { Wiggins } \\
\text { Analytical } \\
\text { Solution }\end{array}$ \\
$\mathbf{q}_{\mathbf{o}}(\mathbf{b b l} /$ day)
\end{tabular}} & \multirow{2}{*}{$\begin{array}{c}\begin{array}{c}\text { Sukarno and } \\
\text { Wisnogroho }\end{array} \\
\begin{array}{c}\mathbf{q}_{\mathrm{o}} \\
\text { (bbl/day) }\end{array}\end{array}$} \\
\hline $\begin{array}{c}P_{\mathrm{wf}} \\
\text { (psi) }\end{array}$ & $\begin{array}{c}\mathbf{q}_{\mathrm{o}} \\
\text { (bbl/day) }\end{array}$ & & & & & & & & & \\
\hline 3810 & 1000 & 937 & 985 & 898 & 967 & 1466 & 974 & 944 & 951 & 1040 \\
\hline 3152 & 4000 & 3969 & 4060 & 4000 & 4000 & 4743 & 4039 & 3987 & 4010 & 4156 \\
\hline 2669 & 6000 & 6000 & 6000 & 6000 & 6000 & 6000 & 6000 & 6000 & 6000 & 6000 \\
\hline 2137 & 8000 & 8037 & 7812 & 7851 & 8027 & 6787 & 7866 & 7991 & 7895 & 7615 \\
\hline 1524 & 10000 & 10131 & 9491 & 9498 & 10192 & 7329 & 9642 & 9998 & 9671 & 8984 \\
\hline 824 & 12000 & 12187 & 10866 & 10714 & 12482 & 7788 & 11177 & 11911 & 11148 & 9984 \\
\hline 390 & 13000 & 13284 & 11431 & 11106 & 13824 & 8055 & 11867 & 12896 & 11776 & 10351 \\
\hline 9 & 13660 & 14136 & 11745 & 11220 & 14959 & 8288 & 12307 & 13634 & 12153 & 10542 \\
\hline $\mathbf{0}$ & & 14155 & 11750 & 11220 & 14985 & 8294 & 12315 & 13650 & 12160 & 10545 \\
\hline \multicolumn{2}{|c|}{$\begin{array}{c}\text { Average absolute } \\
\text { errors }\end{array}$} & $2.3 \%$ & $6.6 \%$ & $10.0 \%$ & $4.2 \%$ & $31.4 \%$ & $4.9 \%$ & $1.1 \%$ & $5.3 \%$ & $11.8 \%$ \\
\hline
\end{tabular}

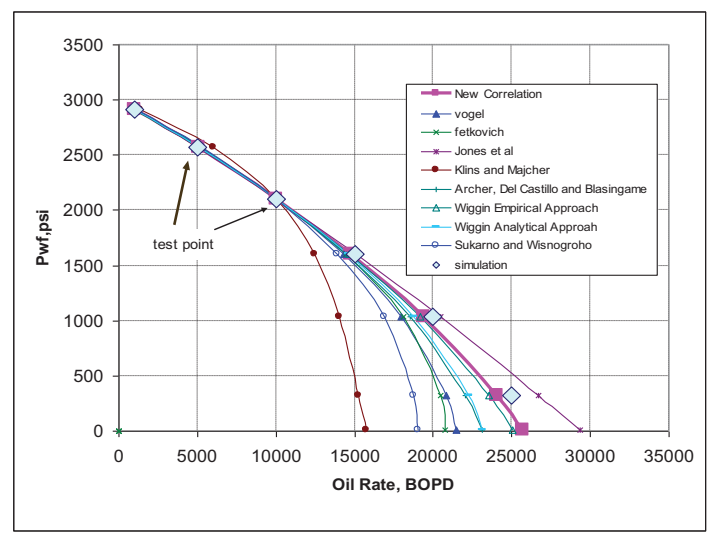

(a)

IPR comparison for synthetic case 1

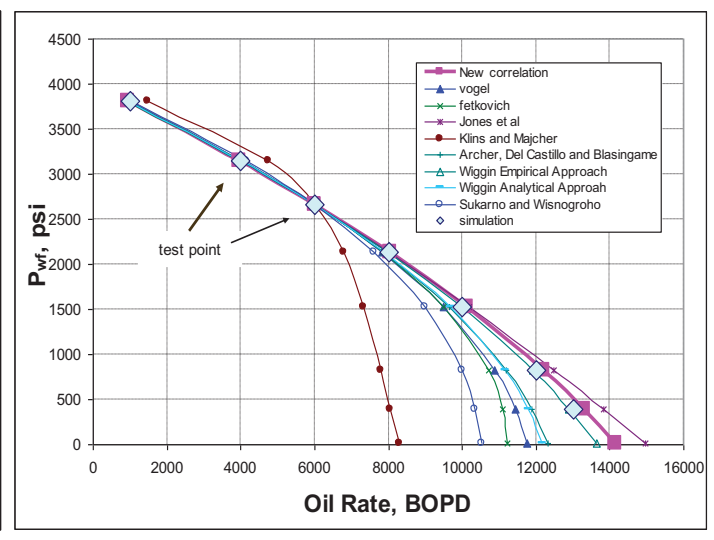

(b)

IPR comparison for synthetic case 2

Fig. (23). IPR comparison of two validation cases from the proposed correlation compared to actual generated from simulation and other commonly used IPR correlations.

\subsection{Field Cases}

Three different field cases from different solution gas-drive fields worldwide were used to test the practical application of the proposed correlation compared to the other widely used correlations in accurately predicting the multi-rate test data. The major difficulties noticed in these field cases are that, most of the multi rate tests taken from wells especially in solution gas-drive reservoirs were obtained with minimum range of draw down as it is practically difficult to design multi rate tests for wells with high drawdown. On the contrary, for the synthetic cases shown above, we have tendency to reach very high drawdown where the bottom hole flowing pressure can reach to extremely low values as shown in Figs. (23a and b) where one is able to test the performance of different correlations at low and high drawdown conditions for better judgement. This problem in most of the multi-rate test data of all the field cases leads to the difficulty in assessing the effectiveness of our proposed correlation compared to the other correlations as all of the correlations give acceptable results at low range of drawdowns which will be observed in the next section of the field cases discussion. 


\subsubsection{Field Case 1: Well 6, Field A [5, 29]}

Field A is solution gas-drive carbonate reservoir; the average gas saturation at the time of the tests was between 10 and $12 \%$. The reservoir was above the critical gas saturation at the time of the tests. The rock and fluid properties and the $\mathrm{C}_{1}$ IPR distinct parameters calculated from the proposed correlation are given in Table (3).

The test consists of seven individual flows, the first four flow rates were run in a normal increasing sequence followed by reducing rate and then increasing rate. Table (4) shows the multi-rate test data taken from this well.

Fig. (24) gives Jones et al. plot for this field case. It seems that two out of the seven test points $\left(\mathrm{P}_{\mathrm{wf}}=1178\right.$ psi \& $\mathrm{P}_{\mathrm{wf}}=1142 \mathrm{psi}$ ) lied out of the straight line trend and it showed that there is an error for these measured points and it must be excluded from using them as test points for the IPR construction. Fig. (25) gives Fetkovich plot for same field case.

Table (5) shows the flow rates estimated for this case for the proposed and commonly used IPR correlations using test point at a flowing bottom hole pressure of $921 \mathrm{psi}$, representing $32 \%$ drawdown for all the correlations with additional one test point for Fetkovich and Jones et al. correlation. As can be seen, the absolute open flow potential (AOF) varies from 420 to $552 \mathrm{BOPD}$ from the different correlations. The largest flow was calculated with Jones et al. correlation, while the smallest one was obtained using Sukarno et al. correlation.

Fig. (26) gives the proposed correlation compared to the other correlations. The average absolute errors between the recorded flow rate data and the estimated rates as shown in Table (5) was $5 \%$ for the proposed correlation, Vogel, Jones et al., Sukarno et al. and Klins and Majcher correlations while it was 6\% for Wiggins Empirical correlation [8, 9] and Fetkovich. The proposed correlation was able to accurately predict the multi-rate test data within a reasonable accuracy compared to the other correlations with all the correlations showing almost same average absolute errors due the small drawdowns of all the test points.

Table 3. Reservoir properties and $\mathrm{C}_{1}$ estimate for field case 1.

\begin{tabular}{|c|c|c|c|c|c|c|c|c|c|c|}
\hline $\mathbf{P}$ & $\mathbf{P}_{\mathbf{b}}$ & $\left(\mathbf{P}_{\mathbf{r}} / \mathbf{P}_{\mathbf{b}}\right)$ & $\mathbf{S}_{\mathrm{gcr}}$ & $\mathbf{S}_{\text {org }}$ & OG EXP & $\mathbf{G ~ E X P}$ & $\mathbf{K}_{\text {row }}$ at $\left(\mathbf{S}_{\text {wrr }}\right)$ & $\begin{array}{c}\mathbf{K}_{\mathrm{rg}} \text { at } \\
\left(\mathbf{1}-\mathbf{S}_{\text {wrr }}-\mathbf{S}_{\text {org }}\right)\end{array}$ & $\mathbf{S k i n}$ & $\mathbf{C}_{\mathbf{1}}$ \\
\hline 1345 & 2020 & 0.67 & 0.05 & 0.4 & 4.1 & 3.1 & 1 & 0.67 & 0 & 0.22 \\
\hline
\end{tabular}

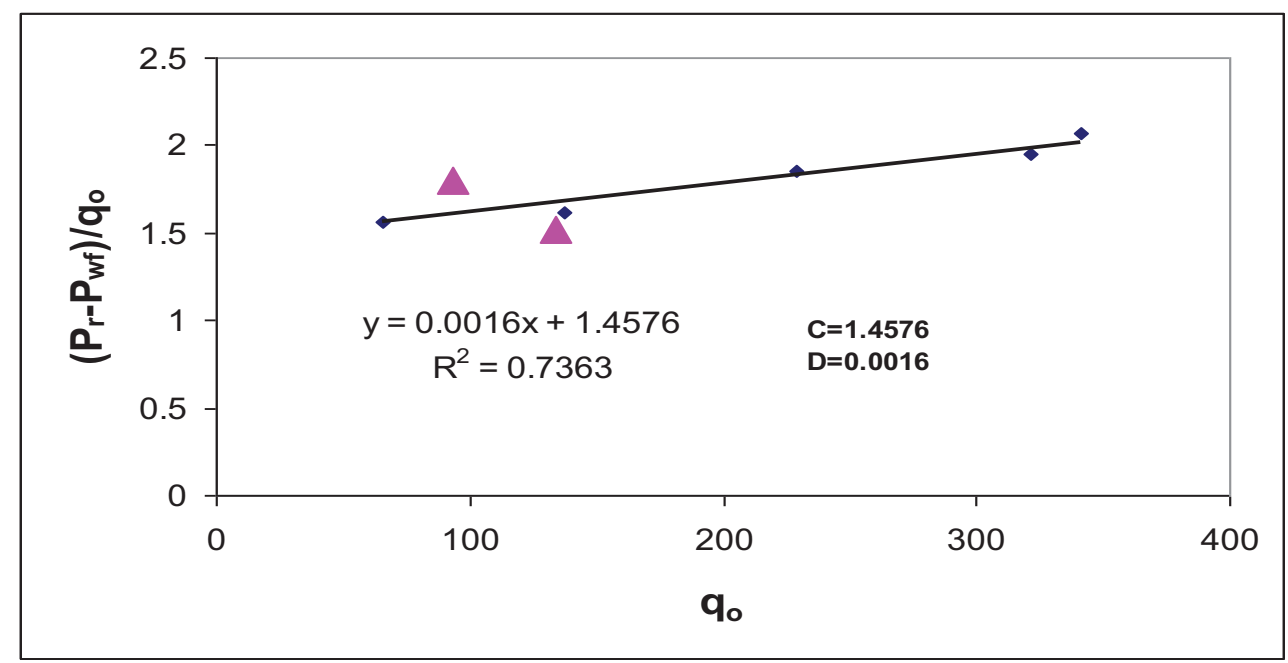

Fig. (24). Jones et al. plot for field case 1. 
Table 4. Multi-rate test data for field case 1.

\begin{tabular}{|c|c|}
\hline Oil Rate (bbl/day) & P $_{\text {wf }}$ (psi) \\
\hline 0 & 1345 \\
\hline 66 & 1242 \\
\hline 93 & 1178 \\
\hline 134 & 1142 \\
\hline 137 & 1123 \\
\hline 229 & 921 \\
\hline 321 & 719 \\
\hline 341 & 638 \\
\hline
\end{tabular}

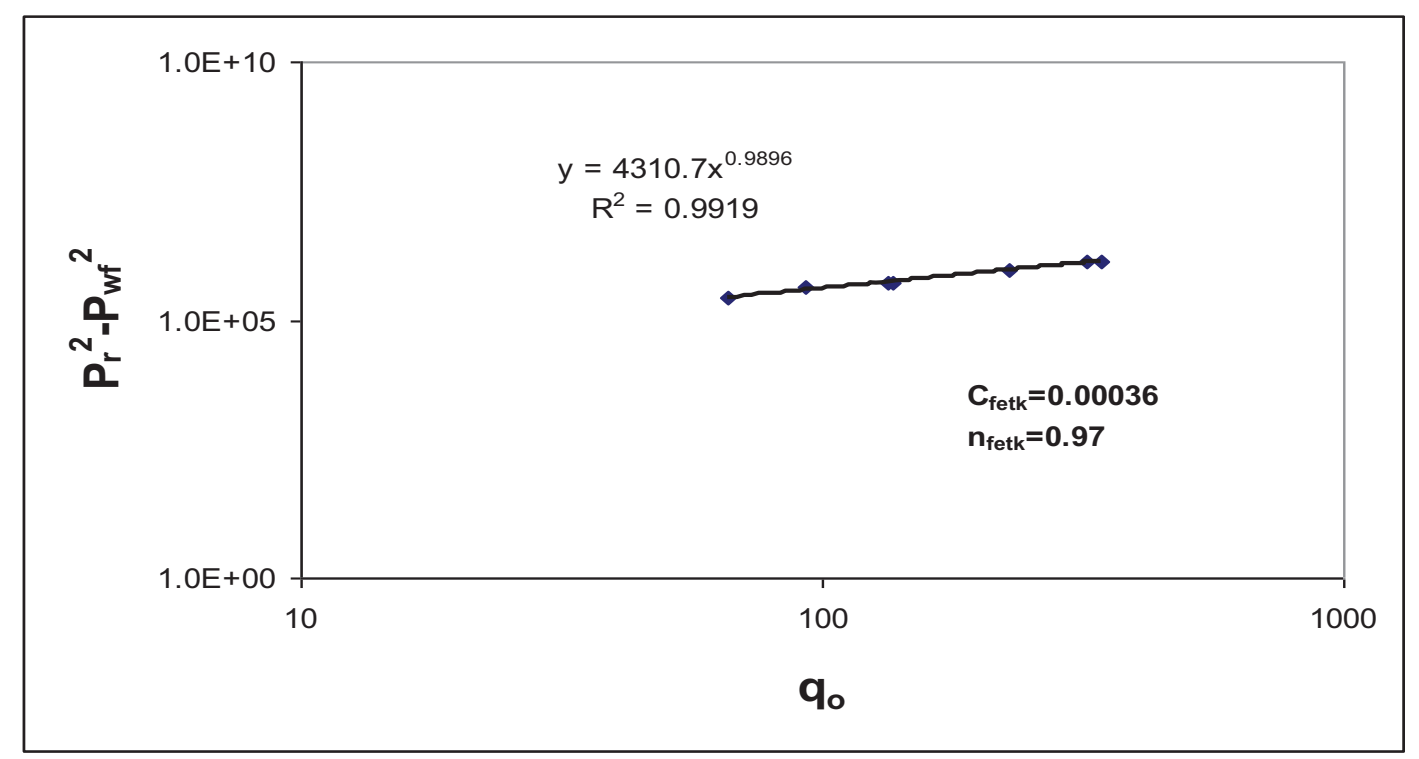

Fig. (25). Fetkovich plot for field case 1.

Table 5. Multi-rate test data and estimated flow rates for field case 1.

\begin{tabular}{|c|c|c|c|c|c|c|c|c|}
\hline Field data & New Correlation & Vogel & Fetkovich & Jones et al. & Klins and Majcher & Wiggins & Sukarno et al. \\
\hline Pwf (psi) & Qo (bbl/day) & Qo (bbl/day) & Qo (bbl/day) & Qo (bbl/day) & Qo (bbl/day) & Qo (bbl/day) & Qo (bbl/day) & Qo (bbl/day) \\
\hline 1345 & 0 & 0 & 0 & 0 & 0 & 0 & 0 & 0 \\
\hline 1242 & $66^{*}$ & 62 & 63 & $66^{*}$ & $66^{*}$ & 65 & 60 & 65 \\
\hline 1178 & 93 & 99 & 99 & 103 & 103 & 103 & 96 & 103 \\
\hline 1142 & 134 & 119 & 119 & 123 & 122 & 123 & 116 & 123 \\
\hline 1123 & 137 & 129 & 129 & 133 & 132 & 133 & 126 & 133 \\
\hline 921 & $229^{*}$ & $229^{*}$ & $229^{*}$ & $229^{*}$ & $229^{*}$ & $229^{*}$ & $229^{*}$ & $229^{*}$ \\
\hline 719 & 321 & 312 & 312 & 305 & 312 & 305 & 320 & 303 \\
\hline 638 & 341 & 341 & 341 & 330 & 343 & 329 & 353 & 327 \\
\hline 400 & & 410 & 409 & 387 & 427 & 386 & 439 & 379 \\
\hline 200 & & 450 & 448 & 414 & 492 & 418 & 499 & 406 \\
\hline 0 & & 474 & 470 & 423 & 552 & 440 & 547 & 420 \\
\hline \multicolumn{2}{|l|}{ Average absolute errors } & $5 \%$ & $5 \%$ & $6 \%$ & $5 \%$ & $5 \%$ & $6 \%$ & $5 \%$ \\
\hline
\end{tabular}




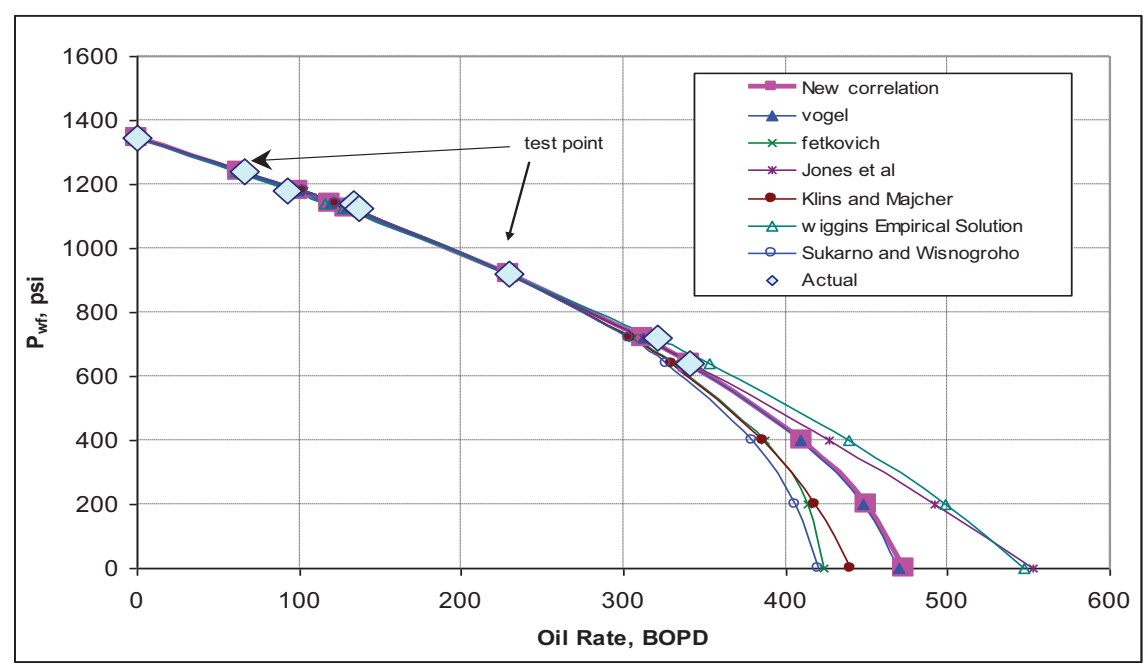

Fig. (26). IPR comparison for field case 1.

\subsubsection{Field case 2: Well B, Keokuk Pool, Seminole County, Oklahoma, December 1934 [29]}

Table (6) gives the reservoir properties and the $\mathrm{C}_{1}$ estimate for this field case. Table (7) shows the multi-rate test data taken from this case. Table (8) shows the flow rates estimated for this case for the proposed and commonly used IPR correlations using test point at a flowing bottom hole pressure of $1196 \mathrm{psi}$, representing $30 \%$ drawdown and another test point at a flowing bottom hole pressure of 1443 psi, representing 16\% drawdown for Fetkovich and Jones et al. correlation. The absolute open flow potential (AOF) varies from 2034 to 2870 BOPD. The largest AOF was calculated from Fetkovich while the smallest one was obtained from Klins and Majcher correlation.

Table 6. Reservoir properties and $C_{1}$ estimate for field case 2.

\begin{tabular}{|c|c|c|c|c|c|c|c|c|c|c|}
\hline $\mathbf{P}$ & $\mathbf{P}_{\mathbf{b}}$ & $\left.\mathbf{( P}_{\mathbf{r}} / \mathbf{P}_{\mathbf{b}}\right)$ & $\mathbf{S}_{\mathrm{gcr}}$ & $\mathbf{S}_{\text {org }}$ & OG EXP & $\mathbf{G ~ E X P ~}$ & $\mathbf{K}_{\mathrm{row}}$ at $\left(\mathbf{S}_{\mathrm{wer}}\right)$ & $\begin{array}{c}\mathbf{K}_{\mathrm{rg}} \text { at } \\
\left(\mathbf{1}-\mathbf{S}_{\mathrm{wrr}}-\mathbf{S}_{\text {org }}\right)\end{array}$ & $\mathbf{S k i n}$ & $\mathbf{C}_{\mathbf{1}}$ \\
\hline 1714 & 3420 & 0.50 & 0.1 & 0.05 & 2.32 & 3.11 & 0.8 & 0.54 & 0.1 & 0.41 \\
\hline
\end{tabular}

Table 7. Multi-rate test data for field case 2.

\begin{tabular}{|c|c|}
\hline Oil Rate (bbl/day) & $\mathbf{P}_{\text {wf }}$ (psi) \\
\hline 0 & 1714 \\
\hline 280 & 1583 \\
\hline 508 & 1443 \\
\hline 780 & 1272 \\
\hline 1125 & 1196 \\
\hline 1335 & 982 \\
\hline
\end{tabular}

Table 8. Multi-rate test data and estimated flow rates for field case 2.

\begin{tabular}{|c|c|c|c|c|c|c|c|c|}
\hline Field data & New Correlation & Vogel & Fetkovich & Jones et al. & Klins and Majcher & Wiggins & Sukarno et al. \\
\hline Pwf (psi) & Qo (bbl/day) & Qo (bbl/day) & Qo (bbl/day) & Qo (bbl/day) & Qo (bbl/day) & Qo (bbl/day) & Qo (bbl/day) & Qo (bbl/day) \\
\hline 1714 & 0 & 0 & 0 & 0 & 0 & 0 & 0 & 0 \\
\hline 1583 & 280 & 311 & 317 & 195 & 231 & 349 & 307 & 331 \\
\hline 1443 & $508^{*}$ & 624 & 632 & $508^{*}$ & $508^{*}$ & 671 & 619 & 650 \\
\hline 1272 & 780 & 978 & 982 & 934 & 910 & 1000 & 975 & 990 \\
\hline 1196 & $1125^{*}$ & $1125^{*}$ & $1125^{*}$ & $1125^{*}$ & $1125^{*}$ & $1125^{*}$ & $1125^{*}$ & $1125^{*}$ \\
\hline
\end{tabular}


(Table 8) contd....

\begin{tabular}{|c|c|c|c|c|c|c|c|c|}
\hline \multicolumn{2}{|c|}{ Field data } & \multirow{2}{*}{\begin{tabular}{|c|} 
New Correlation \\
Qo (bbl/day) \\
\end{tabular}} & \multirow{2}{*}{$\frac{\text { Vogel }}{\text { Qo (bbl/day) }}$} & \multirow{2}{*}{\begin{tabular}{|c|} 
Fetkovich \\
Qo (bbl/day) \\
\end{tabular}} & \multirow{2}{*}{\begin{tabular}{|c|} 
Jones et al. \\
Qo (bbl/day) \\
\end{tabular}} & \multirow{2}{*}{$\begin{array}{c}\text { Klins and Majcher } \\
\text { Qo (bbl/day) }\end{array}$} & \multirow{2}{*}{\begin{tabular}{|c|} 
Wiggins \\
Qo (bbl/day) \\
\end{tabular}} & \multirow{2}{*}{\begin{tabular}{|l|} 
Sukarno et al. \\
Qo (bbl/day) \\
\end{tabular}} \\
\hline Pwf (psi) & Qo (bbl/day) & & & & & & & \\
\hline 982 & 1335 & 1507 & 1488 & 1642 & 2188 & 1418 & 1519 & 1452 \\
\hline 800 & & 1794 & 1750 & 2033 & & 1606 & 1820 & 1673 \\
\hline 600 & & 2068 & 1987 & 2389 & & 1761 & 2117 & 1859 \\
\hline 400 & & 2300 & 2173 & 2653 & & 1875 & 2377 & 1993 \\
\hline 200 & & 2490 & 2307 & 2815 & & 1961 & 2601 & 2081 \\
\hline 0 & & 2638 & 2389 & 2870 & & 2034 & 2788 & 2131 \\
\hline \multicolumn{2}{|c|}{ Average absolute errors } & $18 \%$ & $19 \%$ & $24 \%$ & $33 \%$ & $23 \%$ & $18 \%$ & $20 \%$ \\
\hline
\end{tabular}

* Test Point

Fig. (27) gives the proposed correlation compared to the other correlations. The average absolute errors between the recorded flow rate data and the estimated rates was 18\% for the proposed correlation and Wiggins Empirical correlation [8, 9], 19\% for Vogel, 20\% for Sukarno et al., 23\% for Klins and Majcher, 24\% for Fetkovich, 33\% for Jones et al. correlation. The proposed correlation gives the reasonable error compared to the other correlations used in this case with highest error obtained from the two-point tests which are Fetkovich and Jones et al. correlations. All the singlepoint test correlations including the proposed correlations show almost the same average absolute error due to the low drawdowns of the test points as mentioned in the previous field case.

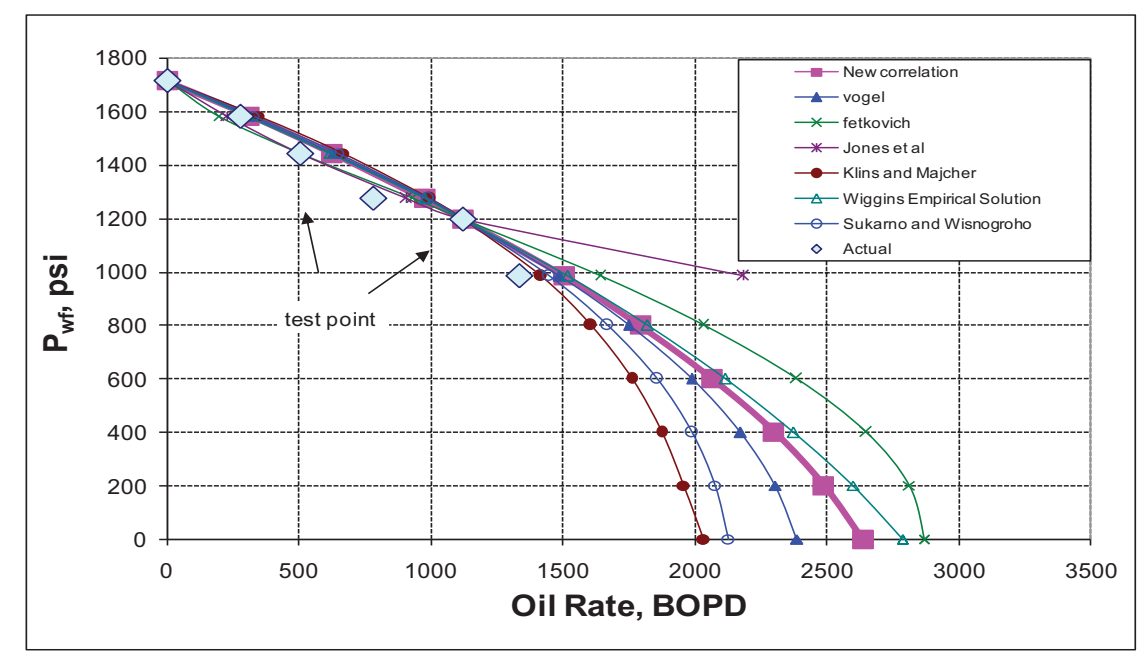

Fig. (27). IPR comparison for field case 2.

\subsubsection{Field case 3: Well B, Keokuk Pool, Seminole County, Oklahoma, August 1935 [29]}

The multi rate test has been repeated for this well from Field Case 2 after 8 months of production with a drop in reservoir pressure from 1714 psi to 1605 psi. Table (9) gives the reservoir properties and the $\mathrm{C}_{1}$ estimate for this field. Table (10) shows the multi-rate test data taken from this well. Table (11) gives the flow rates estimated for this case for the proposed and commonly used IPR correlations using test point at a flowing bottom hole pressure of 1231 psi, representing $23 \%$ drawdown and another test point at a flowing bottom hole pressure of 1381 psi, representing $14 \%$ drawdown for Fetkovich and Jones et al. correlation. As can be seen, the Absolute Open Flow potential (AOF) varies from 1618 to 4907 BOPD. The largest AOF was calculated from Jones et al. correlation, while the smallest one was obtained from Klins and Majcher correlation.

Fig. (28) gives the proposed correlation compared to the other correlations. The average absolute errors between the recorded flow rate data and the estimated rates was 7\% for the proposed correlation, Vogel, Wiggins Empirical correlation, Sukarno et al., and Klins and Majcher while it was 10\% for Fetkovich, 12\% for Jones et al. correlation.

Table 9. Reservoir properties and $C_{1}$ estimate for field case 3.

\begin{tabular}{|c|c|c|c|c|c|c|c|c|c|c|}
\hline $\mathbf{P}$ & $\mathbf{P}_{\mathbf{b}}$ & $\left(\mathbf{P}_{\mathbf{r}} / \mathbf{P}_{\mathbf{b}}\right)$ & $\mathbf{S}_{\text {gcr }}$ & $\mathbf{S}_{\text {org }}$ & OG EXP & $\mathbf{G ~ E X P ~}$ & $\mathbf{K}_{\text {row }}$ at $\left(\mathbf{S}_{\text {wrr }}\right)$ & $\begin{array}{c}\mathbf{K}_{\text {rg }} \text { at } \\
\left(\mathbf{1}-\mathbf{S}_{\text {wrr }}-\mathbf{S}_{\text {org }}\right)\end{array}$ & Skin & $\mathbf{C}_{\mathbf{1}}$ \\
\hline 1605 & 3420 & 0.47 & 0.1 & 0.05 & 2.32 & 3.11 & 0.8 & 0.54 & 2.0 & 0.49 \\
\hline
\end{tabular}


Table 10. Multi-rate test data for field case 3.

\begin{tabular}{|c|c|}
\hline Oil Rate (bbl/day) & P $_{\text {wf }}$ (psi) \\
\hline 0 & 1605 \\
\hline 420 & 1381 \\
\hline 720 & 1231 \\
\hline 850 & 1120 \\
\hline
\end{tabular}

Table 11. Multi-rate test data and estimated flow rates for field case 3.

\begin{tabular}{|c|c|c|c|c|c|c|c|c|}
\hline \multicolumn{2}{|c|}{ Field data } & New Correlation & Vogel & Fetkovich & Jones et al. & Klins and Majcher & Wiggins & Sukarno et al. \\
\hline Pwf (psi) & Qo (bbl/day) & Qo (bbl/day) & Qo (bbl/day) & Qo (bbl/day) & Qo (bbl/day) & Qo (bbl/day) & Qo (bbl/day) & Qo (bbl/day) \\
\hline 1605 & 0 & 0 & 0 & 0 & 0 & 0 & 0 & 0 \\
\hline 1381 & $420^{*}$ & 446 & 451 & $420^{*}$ & $420^{*}$ & 467 & 445 & 459 \\
\hline 1231 & $720^{*}$ & $720^{*}$ & $720^{*}$ & $720^{*}$ & $720^{*}$ & $720^{*}$ & $720^{*}$ & $720^{*}$ \\
\hline 1120 & 850 & 910 & 902 & 931 & 953 & 880 & 911 & 889 \\
\hline 982 & & 1131 & 1107 & 1174 & 1259 & 1048 & 1134 & 1073 \\
\hline 800 & & 1397 & 1343 & 1454 & 1695 & 1226 & 1404 & 1273 \\
\hline 600 & & 1656 & 1558 & 1703 & 2233 & 1372 & 1668 & 1442 \\
\hline 400 & & 1880 & 1724 & 1883 & 2861 & 1478 & 1899 & 1561 \\
\hline 200 & & 2069 & 1843 & 1993 & 3651 & 1555 & 2095 & 1639 \\
\hline 0 & & 2222 & 1915 & 2030 & 4907 & 1618 & 2258 & 1683 \\
\hline
\end{tabular}

* Test Point

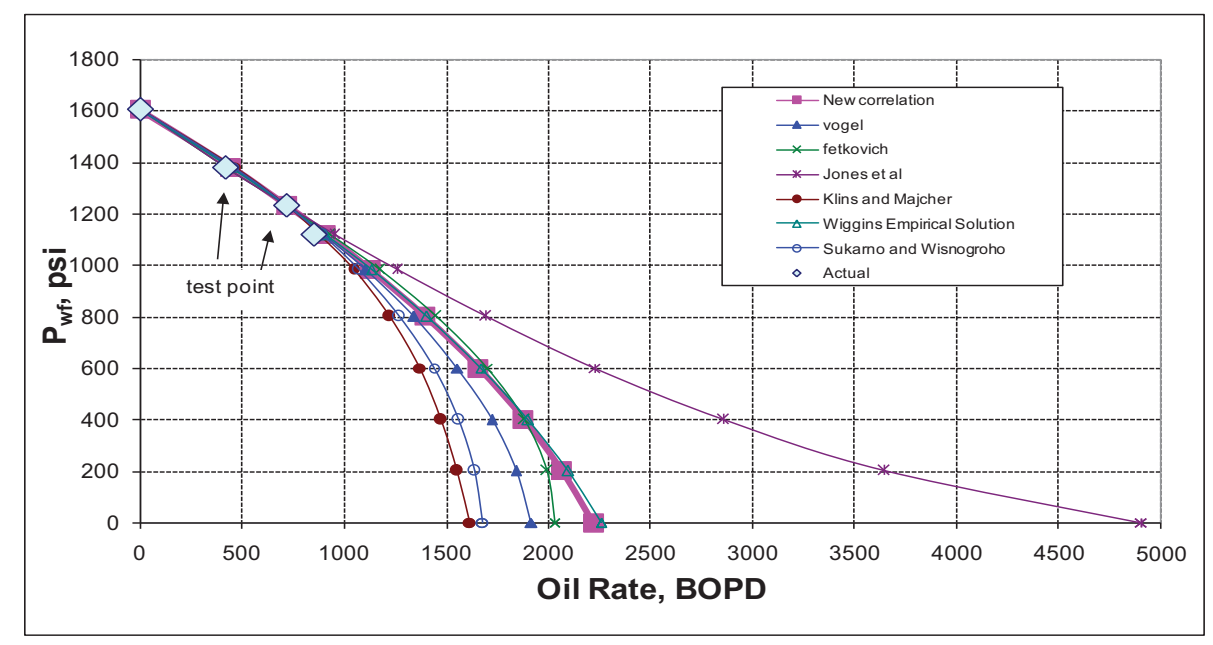

Fig. (28). IPR comparison for field case 3.

This case represents a good opportunity to examine the behavior of the proposed correlation in predicting the future IPR using Eickmeier [30] Equation compared to the other correlations. Eickmeier equation as shown below is used to predict maximum oil rate by knowing the predicted reservoir pressure:

$$
q_{o \max 2}=q_{o \max 1}\left(\frac{P_{r 2}}{P_{r 1}}\right)^{3}
$$

The IPR prediction using Fetkovich is based on assuming constant values for $\mathrm{n}_{\text {fetk }}, \mathrm{C}_{\text {fetk }}$. Case 2 and 3 show minor differences in these values so the assumption of using these values as constant during prediction is valid in this case only.

Table (12) shows the predicted flow rates for field case 3 using data from case 2 for the proposed and the other commonly used correlations. As can be seen, the absolute open flow potential (AOF) varies from 1670 to 2357 BOPD. 
The largest AOF was calculated from Fetkovich while the smallest one was obtained from Klins and Majcher. Fig. (29) gives the proposed correlation compared to the other correlations. The average absolute errors between the recorded flow rate data and the estimated rates was 3\% for the proposed correlation, $6 \%$ for Wiggins Empirical correlation, $7 \%$ for Vogel, $8 \%$ for Klins and Majcher, 9\% for Sukarno et al., and Jones et al. and 10\% for Fetkovich. The proposed correlation gives the least error compared to the other correlations during the prediction which indicates the reasonable accuracy of the proposed correlation in predicting the future IPR.

Field cases $2 \& 3$ present good real field examples to examine the prediction of future IPR using Eickmeier [30] Equation. The results showed that using constant values for Fetkovich and Jones et al. during predicting the future IPR might not be a good assumption in some cases. The proposed correlation that depends on only single-point test shows its good accuracy in predicting the future IPR compared to all the other correlations as seen from Table (12).

Table 12. Multi-rate test data and estimated future flow rates for field case 3.

\begin{tabular}{|c|c|c|c|c|c|c|c|c|}
\hline \multicolumn{2}{|c|}{ Field data } & \multirow{2}{*}{\begin{tabular}{|c|} 
New Correlation \\
Qo (bbl/day)
\end{tabular}} & \multirow{2}{*}{\begin{tabular}{|c|} 
Vogel \\
Qo (bbl/day) \\
\end{tabular}} & \multirow{2}{*}{\begin{tabular}{|c|} 
Fetkovich \\
Qo (bbl/day)
\end{tabular}} & \multirow{2}{*}{\begin{tabular}{|c|} 
Jones et al. \\
Qo (bbl/day) \\
\end{tabular}} & \multirow{2}{*}{$\frac{\text { Klins and Majcher }}{\text { Qo (bbl/day) }}$} & \multirow{2}{*}{\begin{tabular}{|c|} 
Wiggins \\
Qo (bbl/day)
\end{tabular}} & \multirow{2}{*}{\begin{tabular}{|l|} 
Sukarno et al. \\
Qo (bbl/day)
\end{tabular}} \\
\hline Pwf (psi) & Qo (bbl/day) & & & & & & & \\
\hline 1605 & 0 & 0 & 0 & 0 & 0 & 0 & 0 & 0 \\
\hline 1381 & 420 & 435 & 462 & 355 & 411 & 482 & 451 & 478 \\
\hline 1231 & 720 & 702 & 738 & 678 & 739 & 743 & 730 & 749 \\
\hline 1120 & 850 & 887 & 924 & 924 & 1028 & 908 & 924 & 925 \\
\hline 982 & & 1103 & 1134 & 1220 & 1496 & 1082 & 1150 & 1116 \\
\hline 800 & & 1362 & 1376 & 1578 & & 1265 & 1423 & 1324 \\
\hline 600 & & 1614 & 1596 & 1908 & & 1416 & 1691 & 1499 \\
\hline 400 & & 1832 & 1766 & 2154 & & 1525 & 1925 & 1623 \\
\hline 200 & & 2016 & 1888 & 2305 & & 1606 & 2124 & 1704 \\
\hline 0 & & 2166 & 1962 & 2357 & & 1670 & 2289 & 1750 \\
\hline \multicolumn{2}{|c|}{ Average absolute errors } & $3 \%$ & $7 \%$ & $10 \%$ & $9 \%$ & $8 \%$ & $6 \%$ & $9 \%$ \\
\hline
\end{tabular}

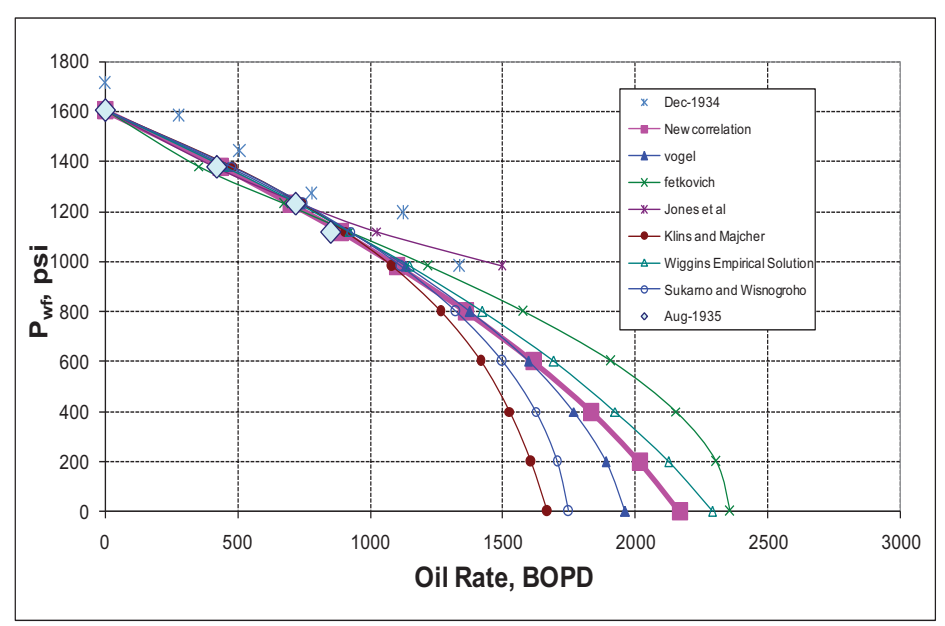

Fig. (29). Future IPR comparison for field case 3.

As shown from the above field cases, variety of field cases with different reservoir rock and fluid properties were presented. Jones at al. Correlation failed to predict the IPR to the AOF for field case 2 due to having a negative turbulent flow coefficient (D), which resulted in calculating unreal value for the flow rates at low bottom hole flowing pressure. This limits the practical application of Jones et al. correlation.

\section{SUMMARY AND CONCLUSION}

Following conclusions can be drawn: 
1. All the IPR correlations which are widely used to predict the deliverability of wells produced from solution gasdrive reservoirs suffer from one common limitation that they are not explicitly function of the different reservoir rock and fluid properties that vary from one reservoir to another. Thus, none of the correlations could be considered as the best method over a wide range of reservoir conditions. One may provide the best estimation for a particular case, while providing the worst for some other cases.

2. The proposed correlation and Vogel correlation used the same base equation with the main difference that Vogel uses a constant distinct $C_{1}$ value of 0.2 while for the proposed correlation, the distinct $C_{1}$ value varies depending on reservoir rock and fluid properties which could vary from one reservoir to another. It was shown in the 550 generated reservoir cases that $C_{1}$ distinct values can range from 0.1 to 0.9 . This expands the range of application of the proposed correlation compared to the others.

3. The proposed correlation showed good accuracy compared to the other widely used correlations in predicting the true multi-rate test data as shown in the different synthetic and field cases presented in this work. The synthetic cases which reached to drawdown of almost $99 \%$ showed that the proposed correlation gives less error compared to the other correlations especially compared to Vogel correlation as both use the same equation with only difference in the distinct $\mathrm{C}_{1}$ value used in both. For the field cases due to the practical difficulty of the field cases to have test points at higher draw down (the maximum drawdown used was $30 \%$ of the reservoir pressure), so the effectiveness of the proposed model compared to the rest of the models cannot be assessed properly at very low pressure (high draw down). However, the proposed correlation did not show any severe discrepancy compared to the other correlations in predicting the wells deliverability.

4. The proposed correlation was also examined for predicting the future IPR as shown in the Field cases 2 and 3 and the results show its good accuracy compared to all the other correlations. This is in addition to the failure of Fetkovich and Jones et al. to predict accurately the IPR in some of the cases due to the assumption of using constant values of Fetkovich and Jones et al. parameters during prediction.

5. The most important feature of the proposed correlation is its dependency on many reservoir rock and fluid properties that proved to highly affect the IPR modeling in solution gas-drive reservoirs based on the sensitivity study done in this work. This will allow the user to use all the available data to accurately predict the IPR performance rather than using any of the current empirical correlation that depends on specific reservoir rock and fluid properties or the analytical correlation that is rather difficult to be applied or does not cover a wide range of reservoir data.

\section{NOMENCLATURE}

\begin{tabular}{|c|c|c|}
\hline$\gamma_{0}$ & $=$ & Oil gravity \\
\hline$\gamma_{w}$ & $=$ & Water gravity \\
\hline$\gamma_{g}$ & $=$ & Gas gravity \\
\hline$\mu_{0}$ & $=$ & Oil viscosity, $\mathrm{cp}$ \\
\hline$\mu_{W}$ & $=$ & Water viscosity, $\mathrm{cp}$ \\
\hline Bo & $=$ & Oil formation volume factor, bbl/stb \\
\hline $\mathbf{C}$ & $=$ & Jones et al. laminar-flow coefficient, psi/stb/day \\
\hline $\mathbf{C}_{\text {fetk }}$ & $=$ & Fetkovich productivity index of the reservoir (PI), stb/day/psi2n \\
\hline D & $=$ & Jones et al. turbulence coefficient, psi/ (stb/day)2 \\
\hline GEXP & $=$ & Gas relative permeability exponent that affects the curvature of $\mathrm{Krg}$ \\
\hline h & $=$ & Formation thickness, $\mathrm{ft}$ \\
\hline $\mathbf{J}$ & $=$ & Productivity index of the reservoir, bbl/day/psi \\
\hline $\mathbf{K}_{\mathrm{h}}$ & $=$ & Horizontal permeability, md \\
\hline$K_{\mathrm{rg}}$ at $\left(1-\mathrm{S}_{\mathrm{wcr}}-\mathrm{S}_{\mathrm{org}}\right)$ & $=$ & Relative permeability to gas at (1-Swcr-Sorg), fraction \\
\hline $\mathbf{K}_{\mathrm{ro}}$ & $=$ & Oil relative permeability, fraction \\
\hline$K_{\text {row }}$ at $\left(\mathbf{S}_{\text {wcr }}\right)$ & $=$ & Relative permeability to oil at Swcr, fraction \\
\hline$K_{\text {rw }}$ at $\left(S_{\text {orw }}\right)$ & $=$ & Relative permeability to water at Sorw, fraction \\
\hline $\mathbf{K}_{\mathbf{v}}$ & $=$ & Vertical permeability, md \\
\hline $\mathbf{m}_{\mathbf{k}}$ & $=$ & Khasanov et al. exponent \\
\hline
\end{tabular}




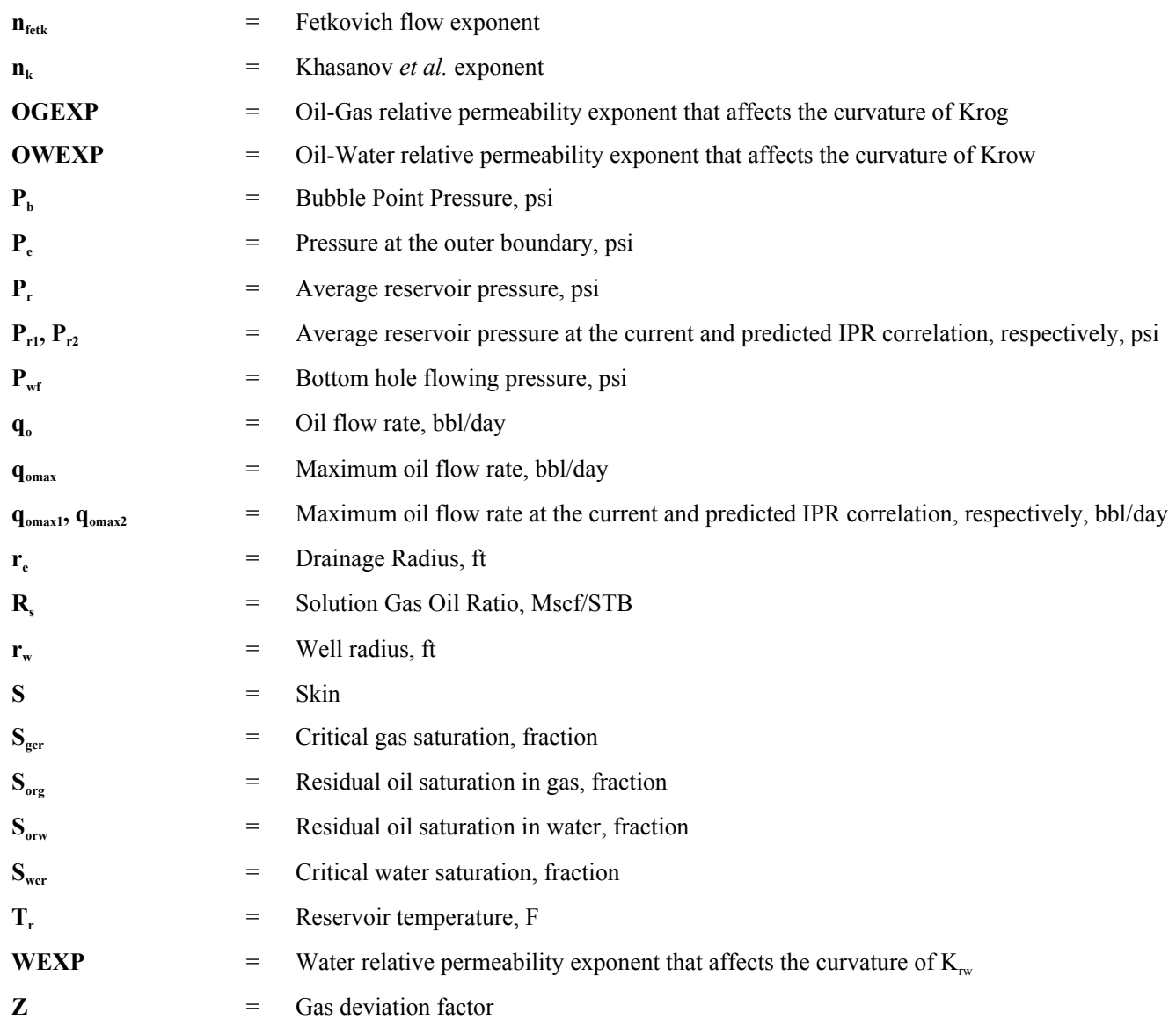

\section{ETHICS APPROVAL AND CONSENT TO PARTICIPATE}

Not applicable.

\section{CONSENT FOR PUBLICATION}

Not applicable.

\section{CONFLICT OF INTEREST}

The authors declare no conflict of interest, financial or otherwise.

\section{ACKNOWLEDGEMENT}

Declared None.

\section{REFERENCES}

[1] H.H. Evinger, and M. Muskat, "Calculation of Theoretical Productivity Factors", Trans. Metall. Soc. AIME, vol. 146, pp. 126-139, 1942. [http://dx.doi.org/10.2118/942126-G]

[2] E.L. Rawlins, and M.A. Schellhardt, "Backpressure Data on Natural Gas Wells and Their Application to Production Practices”, Monograph Series 7, U.S. Bureau of Mines., American Gas Association, Lord Baltimore Press, 1935.

[3] W.E. Gilbert, "Flowing and Gas-Lift Well Performance", In: American Petroleum Institute Proceedings, 1954, pp. $126-157$.

[4] J.V. Vogel, "Inflow Performance Relationships for Solution Gas-Drive Wells", J. Pet. Technol., vol. 20, pp. 83-92, 1968. [http://dx.doi.org/10.2118/1476-PA]

[5] M.J. Fetkovich, "The Isochronal Testing of Oil Wells", In: SPE Annual Meeting, September 30-October 3, Las Vegas, NV, 1973. [http://dx.doi.org/10.2118/4529-MS]

[6] L.G. Jones, E.M. Blount, and O.H. Glaze, "Use of Short Term Multiple Rate Flow Tests to Predict Performance of Wells Having Turbulence", In: SPE Annual Technical Meeting and Exhibition, Oct. 3-6, New Orleans, 1976. [http://dx.doi.org/10.2118/6133-MS] 
[7] J.M. Richardson, and A.H. Shaw, "Two-Rate IPR Testing - A Practical Production Tool", J. Can. Pet. Technol., vol. 21, pp. 57-61, 1982. [http://dx.doi.org/10.2118/82-02-01]

[8] M.L. Wiggins, "Inflow Performance of Oil Wells Producing Water", Ph.D. dissertation, College Station, TX, Texas A\&M University, 1991.

[9] M.L. Wiggins, "Generalized Inflow Performance Relationships for Three-Phase flow", SPE Production Operations Symposium Oklahoma City : 1993, March 21-23. [http://dx.doi.org/10.2118/25458-MS]

[10] M.A. Klins, and M.W. Majcher, "Inflow Performance Relationships for Damaged or Improved Wells Producing Under Solution-Gas Drive", J. Pet. Technol., vol. 44, pp. 1357-1363, 1992. [http://dx.doi.org/10.2118/19852-PA]

[11] P. Sukarno, and A. Wisnogroho, "Generalized Two-Phase IPR Curve Equation under Influence of Non-linear Flow Efficiency", In: Society of Indonesian Petroleum Engineers Production Optimization International Symposium Conference Proceeding, Bandung, Indonesia, 1995.

[12] M.L. Wiggins, J.L. Russel, and J.W. Jennings, "Analytical Inflow Performance Relationships for Three Phase Flow in Bounded Reservoirs", In: SPE Western Regional Meeting, March 30-April 1, California, 1992. [http://dx.doi.org/10.2118/24055-MS]

[13] Y. Del Castillo, "New Inflow Performance Relationships for Gas Condensate Reservoirs", M.S. Thesis, College Station, TX, Texas A \& M University, May 2003.

[14] R.A. Archer, Y. Del Castillo, and T. Blasingame, "New Perspectives on Vogel Type IPR Models for Gas Condensate and Solution-Gas Drive Systems", SPE Production Operations Symposium, 2003 Oklahoma, OK [http://dx.doi.org/10.2118/80907-MS]

[15] M. Abdel Salam, "Developing New Inflow Performance Relationship Correlation for Solution Gas Drive Reservoirs Using Non-Parametric Regression Technique", Master Thesis, Cairo University, Giza, Egypt, 2008.

[16] Z. Haiquan, L. Yingchuan, W. Yulian, L. Chengjian, and L. Wei, "A New General Formula for Dimensionless Well Inflow Performance Relationship", In: SPE Asia Pacific Oil and Gas Conference and Exhibition, Jakarta, Indonesia, 30 October-1 November, 2007.

[17] D. Ilk, R. Camacho Velazquez, and T. Blasingame, "Inflow Performance Relationship (IPR) for Solution-Gas-Drive Reservoirs: Analytical Considerations", SPE Annual Technical Conference and Exhibition, 2007 Anaheim, California [http://dx.doi.org/10.2118/110821-MS]

[18] A. Jahanbani, and S.R. Shadizadeh, "Determination of Inflow Performance Relationship (IPR) by Well Testing", Canadian International Petroleum Conference (CIPC), 2009 Calgary, Alberta [http://dx.doi.org/10.2118/2009-086]

[19] M. Elias, A. El-banbi, K.A. Fattah, and E. El-Tayeb, "New Inflow Performance Relationship for Solution Gas-Drive Oil Reservoirs", SPE Annual Technical Conference and Exhibition, 2009 New Orleans, Louisiana [http://dx.doi.org/10.2118/124041-MS]

[20] M. Khasanov, V. Krasnov, R. Khabibullin, and T. Musabirov, "Self Consistent Approach to Construct Inflow Performance Relationship for Oil Well", SPE Russian Oil and Gas Exploration and Production Technical Conference and Exhibition, 2012 Moscow, Russia

[21] K.E. Brown, "Overview of Artificial Lift Systems", J. Pet. Technol., vol. 34, pp. 2384-2396, 1982. [http://dx.doi.org/10.2118/9979-PA]

[22] D.J. Avery, and R.D. Evans, "Design Optimization of Plunger Lift System", Tianjin, China, 1988. [http://dx.doi.org/10.2118/17585-MS]

[23] X. Yu, H. Xia, Y. Zhang, and J. Li, "Calculation of IPR Curves of Oil Wells for Polymer Flooding Reservoirs", SPE Annual Technical Conference and Exhibition, 1997 San Antonio, Texas [http://dx.doi.org/10.2118/38936-MS]

[24] B. Guo, K. Ling, and A. Ghalambor, "A rigorous Composite-IPR for Multi-Lateral Wells", SPE Annual Technical Conference and Exhibition, 2006 San Antonio, Texas

[http://dx.doi.org/10.2118/100923-MS]

[25] Roxar, "MORE Manual - Version 6.3, 2006.

[26] L. Breiman, and J.H. Friedman, "Estimating Optimal Transformations for multiple Regression and Correlation", J. Am. Stat. Assoc., vol. 80, pp. 580-598, 1985. [http://dx.doi.org/10.1080/01621459.1985.10478157]

[27] G. Xue, A. Datta-Gupta, P. Valko, and T.A. Blasingame, "Optimal Transformations for Multiple Regression: Application to Permeability Estimation from Well Logs", SPE Formation Evaluation Journal, vol. 12, pp. 85-93, 1997. [http://dx.doi.org/10.2118/35412-PA]

[28] W.D. Mc Cain Jr, R.B. Soto, P.P. Valko, and T.A. Blasingame, "Correlation of Bubble Point Pressures for Reservoir Oils - A Comparative Study", In: SPE Eastern Regional Conference and Exhibition, 1998 pp. 267-275 Pittsburgh, PA.

[29] F. Gallice, "A Comparison of Two-Phase Inflow Performance Relationships", M.S. thesis, University of Oklahoma, Norman, Oklahoma, 1997. 
[30] J. R. Eickmeier, "How to Accurately Predict Future Well Productivities", World Oil, 1968.

(C) 2017 Daoud et al.

This is an open access article distributed under the terms of the Creative Commons Attribution 4.0 International Public License (CC-BY 4.0), a copy of which is available at: https://creativecommons.org/licenses/by/4.0/legalcode. This license permits unrestricted use, distribution, and reproduction in any medium, provided the original author and source are credited. 